\title{
Multi-Source Data Analysis of Mesoscale Eddies and Their Effects on Surface Chlorophyll in the Bay of Bengal
}

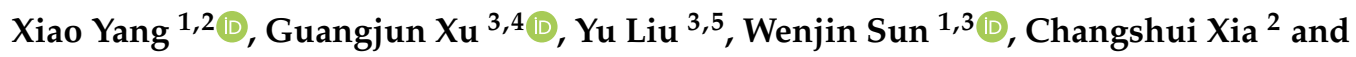 \\ Changming Dong 1,3,* \\ 1 School of Marine Sciences, Nanjing University of Information Science and Technology, \\ Nanjing 210044, China; yx@nuist.edu.cn (X.Y.); sunwenjin@nuist.edu.cn (W.S.) \\ 2 First Institute of Oceanography, Ministry of Natural Resources, Qingdao 266101, China; xiacs@fio.org.cn \\ 3 Southern Laboratory of Ocean Science and Engineering (Guangdong Zhuhai), Zhuhai 519000, China; \\ gjxu@gdou.edu.cn (G.X.); liuyuhk@zjou.edu.cn (Y.L.) \\ 4 College of Electronic and Information Engineering, Guangdong Ocean University, Zhanjiang 524088, China \\ 5 Marine Science and Technology College, Zhejiang Ocean University, Zhoushan 316000, China \\ * Correspondence: cmdong@nuist.edu.cn; Tel.: +86-025-5869-5733
}

Received: 26 September 2020; Accepted: 21 October 2020; Published: 23 October 2020

\begin{abstract}
Mesoscale eddies are important to ocean circulation due to their roles in the transport of mass, energy, and heat. This study employs a combination of data sources to initiate a statistical analysis of eddy spatiotemporal characteristics in the Bay of Bengal (BOB) to elucidate the sea surface and vertical structures of the eddies and their impacts on sea surface chlorophyll (Chl) distributions. The results suggest that 1237 cyclonic eddies (CEs) and 1121 anticyclonic eddies (AEs) were detected in 26 years. The number of two eddy polarities was almost the same, and most of them spread to the west or southwest direction. The vertical change of temperature (T) and salinity (S) caused by the eddies is studied and the anomalous eddies, i.e., a CE (AE) eddy with warm (cold) water at the center, are mainly distributed on the northeast side of the Island of Sri Lanka. Furthermore, CEs are found to increase $\mathrm{Chl}$ concentration in the surrounding sea by approximately $11.15 \%$, while AEs decrease concentrations also by approximately $11.25 \%$. Changes in Chl concentrations occur most rapidly during the mature and intensification eddy phases. Observations also indicate that the strong local current and wind fields are the primary mechanisms in eddy generation.
\end{abstract}

Keywords: Bay of Bengal; mesoscale eddies; vector-geometry eddy detection; eddy characteristics; sea surface chlorophyll

\section{Introduction}

A diverse range of dynamic processes exist on an equally diverse assortment of scales in the ocean, among which mesoscale eddies are the most common mesoscale phenomena [1]. Temporally, they may last for dozens of days to months, and spatially they can range from dozens to hundreds of kilometers. Moreover, the distribution of mesoscale eddies throughout the global ocean is not uniform, and hence can be concentrated in specific areas conducive to their generation and maintenance. Through a host of processes such as Ekman pumping, vertical convection, and eddy trapping, these eddies induce anomalous heat and salt transport and mass exchange, which in turn exert an effect on the survival and reproduction of living organisms [2-4]. Since the 1970s, oceanographers have investigated mesoscale eddies employing a variety of methods inclusive of, but limited to, direct observations, numerical simulation, and theoretical studies $[5,6]$. Recently, progress in eddy research has accelerated through the use of space-borne satellite sensors [7-12]. 
As a marginal sea in the north Indian Ocean, the Bay of Bengal (BOB) has a depth exceeding $5000 \mathrm{~m}$ (See Figure 1) and is an ideal testbed to investigate the influences of mesoscale eddies on regional chlorophyll (Chl) concentration due to the large number of eddies that are generated through complex air-sea interactions, interweaving islands, and strong coastal boundary currents (see Figure 2) [13-16].

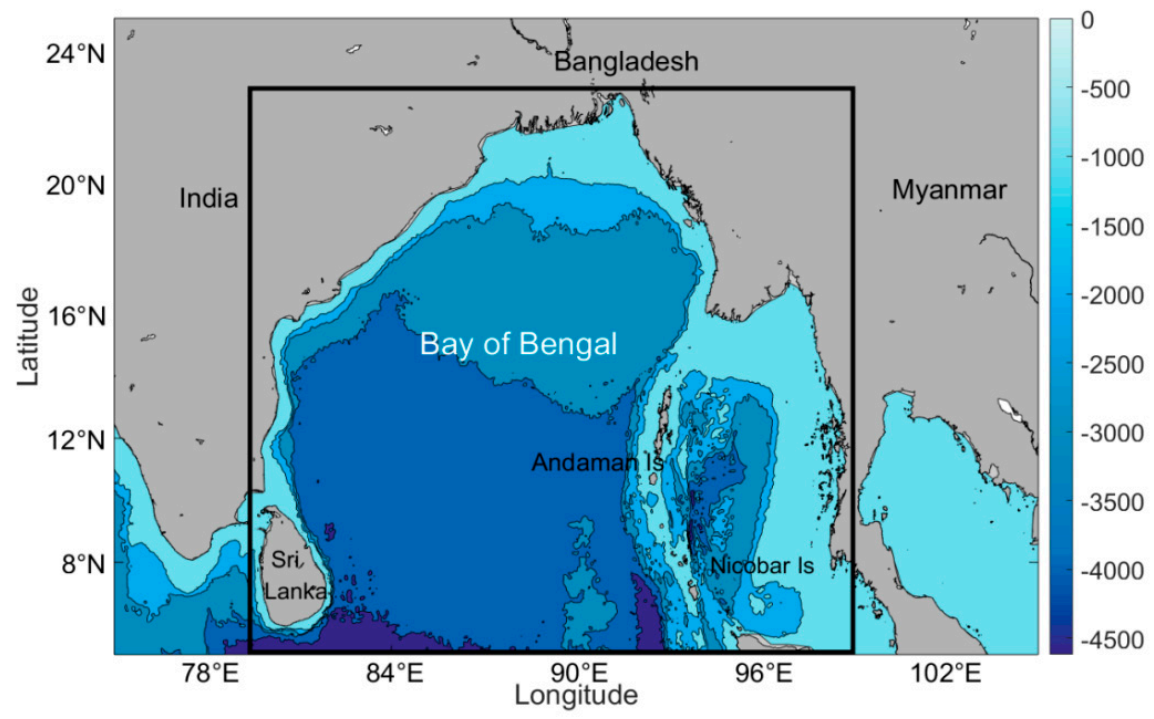

Figure 1. Bathymetry of the Bay of Bengal (BOB) derived from ETOPO1 (1 arc-minute global relief model of Earth's surface that integrates land topography and ocean bathymetry). The black rectangle covers the study area $\left(5-23^{\circ} \mathrm{N}, 79-99^{\circ} \mathrm{E}\right)$; (shaded: the ocean depth, unit: $\left.\mathrm{m}\right)$.
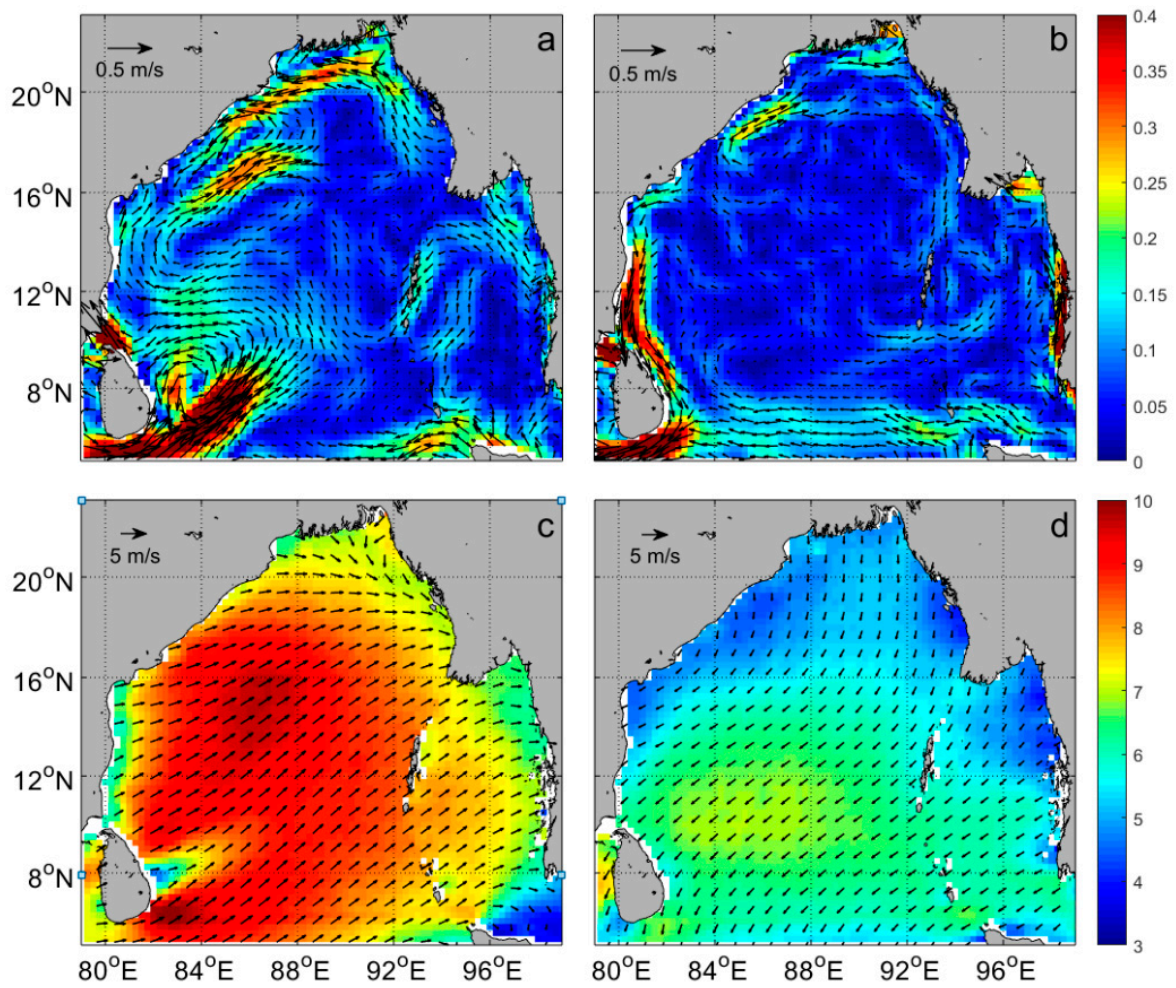

Figure 2. Upper panels: average surface currents in summer (June, July and August) (a) and winter (December, January and February) (b) over the 1993-2018, 26-year period (unit: m/s). Lower panels: average surface wind speed in summer (c) and winter (d) over the 2007-2018 period (unit: $\mathrm{m} / \mathrm{s}$ ). The vectors correspond to surface wind speed and direction. 
Later studies on $\mathrm{BOB}$ mesoscale eddies have relied mainly on sporadic remote-sensing observations and voyage observations, often near basin coastlines [17-19] thus leaving the inner central and southern gulf devoid of in-depth analyses. In recent years, eddy research on the gulf has gradually become comprehensive. Using two years of satellite altimeter in conjunction with ship data, Eigenheer et al. [20] analyze the circulation characteristics and identify clear seasonal signals in the boundary current reversals twice per year that lead the reversal of the local monsoon wind field by several months. Chen et al. [21] use several years of merged satellite data to comprehensively analyze the spatiotemporal distribution of the mesoscale eddies in the $\mathrm{BOB}$ and various mechanisms that may cause changes to eddy statistics on interannual timescales. There, it is suggested that baroclinic instability is the main mechanisms which caused eddy activity at interannual scale, mainly along the eastern coastlines, and that changes in eddy statistics are correlated with El Niño Southern Oscillation (ENSO) events. Cheng et al. [22] find elevated levels of eddy kinetic energy (EKE) in the western part of the BOB, and that eddies in the central BOB largely influence the seasonal variation of sea-level height. Cui et al. [23] use satellite altimeters to study the statistical characteristics of mesoscale eddies in the BOB, uncovering that the most noticeable seasonal change is that cyclonic eddies (CEs) tend to occur mostly in spring, and anticyclonic eddies (AEs) in the summer. Dandapat et al. [24] combine altimeter and Array for Real-Time Geostrophic Oceanography (Argo) data to investigate the three-dimensional structure of mesoscale eddies on the western boundary of the $\mathrm{BOB}$, showing that the formation of eddies is very sensitive to wind intensity, and that both CEs and AEs possess single-core vertical structures that are enhanced to a degree in the western boundary deep sea. Chang et al. [25] use Archiving Validation and Interpolation of Satellite Oceanographic Data (AVISO) and Quick Scatterometer (QuickSCAT) data to conduct a detailed analysis of the seasonal changes of eddies in $\mathrm{BOB}$ and demonstrate the related mechanisms of eddy generation. The study further shows that the eddy is mainly constrained by the $\beta$-effect and that both CEs and AEs are mainly shifted towards the equator.

As far as the mesoscale eddy itself is concerned, it has an important influence on global climate, productivity, ocean circulation, fishery development, fresh water transportation and other aspects. For the marine ecological environment, phytoplankton $\mathrm{Chl}$ is an important parameter in environmental assessment as its concentration can be used to estimate the degree of eutrophication, nutrient saturation and organic pollution a body of water is experiencing [26]. The distribution of $\mathrm{Chl}$ is related to the phytoplankton and primary productivity as they account for approximately half of the global total photosynthesis [27-29], and sequesters an estimated amount, thus affecting marine biological resources and fisheries production. Among them, the essential nutrients photosynthesis, such as nitrates and sulfates, are transported predominantly by mesoscale processes such as fronts, upwellings, and eddies up from the sea bottom to the sea surface where photosynthesis occurs and can induce changes in Chl concentration [30-32]. Due to their dynamic transport, mesoscale eddies have been reported to be responsible for modulating $10 \%$ to $15 \%$ of phytoplankton photosynthesis activities [33-37]. For example, Murtugudde et al. [38] find that a phytoplankton bloom event in the eastern Indian Ocean in 1997 coincided with the occurrence of an abnormal upwelling along Sumatra. Vinayachandran et al. [39] discover that due to the input of fresh water from rivers and the influence of monsoons, a strong stratification is formed in the sea area, and the vertical transport of nutrients is hindered to some extent. Kumar et al. [40,41] find that during the summer monsoon, when the upper ocean is highly stratified, the eddy in the BOB plays an important role in the vertical transport of nutrients from the barren area to the eutrophic area; and then they use field measurement data to study cold-core eddies at the basin's western boundary and find that eddy pumping not only affects the local seawater temperature, but also the distribution of nutrients. Chelton et al. [42] use a variety of satellite observation data to provide a global overview of how eddy influence $\mathrm{Chl}$ anomalies. Singh et al. [43] study the distribution of sea surface nutrients in the northern part of the gulf, and the results show that eddies and freshwater imports could increase the primary production in the area. Gonaduwage et al. [44] comprehensively explore the effects of thermal salt transport caused by mesoscale eddies in the BOB. The study divides the bay into four parts, and discusses different mechanisms for different parts. Early shipborne data 
indicated that primary productivity in the $\mathrm{BOB}$ is relatively low compared to the adjacent Arabian Sea [45]. Therefore, the transfer of nutrients and heat caused by mesoscale eddies becomes particularly important for the environmental and ecological production of the bay. It is necessary to study the effects of mesoscale eddies on $\mathrm{Chl}$ in the BOB to evaluate primary productivity.

On the whole, through modulating factors such as ocean circulation, freshwater transport, ocean productivity and fisheries, eddies have a strong influence on the global climate and human activities. Although a great deal of research has been geared towards investigating the spatiotemporal distribution characteristics of mesoscale eddies and their effects in the BOB, most of those studies are limited to the sea surface and concentrate on the western and southern boundaries of the bay. Eddy vertical structures remains to be elucidated, and in light of the significant effect of mesoscale eddies on the exchange of energy and mass in the global ocean and their effects on the marine environment, a study of the effect of eddies on the distribution of $\mathrm{Chl}$ concentration can provide a scientific basis for the assessment of marine fishery production, and help to understand the status of the marine biological resources and the ecological environment.

Consequently, a statistical analysis of the spatiotemporal distribution and physical characteristics of mesoscale eddies and their effects on Chl concentrations is performed in the BOB over the 1993-2018, 26-year period using a combination of Argo ocean temperature/salinity (T/S) profiles and satellite data in conjunction with a vector geometry-based eddy detection scheme. The remainder of the paper is structured as follows: Section 2 describes the study area, datasets and methodologies employed, Section 3 presents the results of the study, Section 4 undertakes a discussion, and Section 5 draws the conclusion.

\section{Materials and Methods}

\subsection{Materials}

\subsubsection{Satellite Data}

The ocean mesoscale eddy analysis used the French space agency's AVISO multi-satellite merged altimeter data product, which is composed of the Data Unification and Altimeter Combination System (DUACS) of the Topography Experiment/ Poseidon monitored global ocean circulation (TOPEX/POSEIDON), Jason-1, European remote sensing satellite/ Environmental Satellite (ERS/Envisat), amongst other platforms. In this paper, daily data with a spatial resolution of $1 / 4^{\circ} \times 1 / 4^{\circ}$ were selected. The time span of the dataset selected was from 1 January 1993 to 31 December 2018, and included feature information such as the sea level anomaly (SLA), geostrophic velocity anomalies, and absolute geostrophic velocity.

For the ocean color data, an eight-day average product of multi-satellite merged data with a spatial resolution of $4 \mathrm{~km} \times 4 \mathrm{~km}$ which can be obtained from the Globcolour database provided by http://hermes. acri.fr. The data incorporate Sea-viewing Wide Field-of-view senor (SeaWiFS), Moderate-resolution Imaging Spectroradiometer (MODIS), Medium-resolution Imaging Spectrometer Instrument (MERIS), Ocean and Land Colour Instrument (OLCI), and Visible Infrared Imaging Radiometer (VIIRS) which provide a variety of information on biogeochemistry, sea surface and atmospheric optical characteristics. It should be noted that merged products offer improved spatiotemporal coverage of water color data while minimizing the impact of noise. The period of the data used was from 29 August 1997 to 31 December 2018. To study the temporal evolution of Chl-a around an eddy and the eddies' effect on Chl-a, an area the size of 2.5 times a given eddy's range is selected for study.

Sea surface temperature (SST) data used in a separate eddy detection and tracking algorithm for comparison to the previously described geostrophic velocity anomaly, vector geometry-based eddy detection algorithm were derived from daily data acquired from the National Aeronautics and Space Administration (NASA)'s Physical Oceanography Distributed Active Archive Center on a spatial resolution of $25 \mathrm{~km} \times 25 \mathrm{~km}$ over the 1993-2018, 26-year period. Data can be acquired at https://www.ncei.noaa.gov/thredds/catalog/OisstBase/NetCDF/V2.0/AVHRR/catalog.html. 
Wind field data were acquired from the Advanced Scatterometer (ASCAT) version 2.1 dataset as maintained by Remote Sensing Systems. Daily $10 \mathrm{~m}$ wind speed and direction data over the 2007-2018, 11-year period at a spatial resolution of $1 / 4^{\circ} \times 1 / 4^{\circ}$ were obtained from ftp://ftp.remss.com/ascat/ metopa/bmaps_v02.1.

\subsubsection{Argo Float}

Daily temperature and salinity profiles were derived from the Argo float maintained by the Argo International Project from 1999 to 2018, and were downloaded from ftp://ftp.ifremer.fr/ifremer/argo/ geo/indian_ocean/. Argo data within the area of 2 times the radius of a mesoscale eddy were selected to analyze the thermohaline effects of eddies at different depths.

\subsection{Methods}

In the present study, an Eulerian eddy detection method was used to identify and track eddies by an automatic algorithm based on geostrophic velocity vector proposed by Nencioli et al. [46]. This algorithm has been successfully applied in many regions [47-52]. Briefly, the eddy detection and tracking method includes three steps: (1) determine the eddy center, (2) extract the eddy boundary, and (3) track the eddy lifespan.

\subsubsection{Determine the Eddy Center}

Using the geostrophic balance relationship, the sea surface anomaly field is converted into a geostrophic velocity field, and mesoscale eddies on the sea surface are automatically detected from the velocity field. The eddy velocity field has a particular characteristic: the velocity near the center of the eddy has a minimum value. After determining the approximate eddy center, it is determined by the geometry of the velocity vector through four limiting conditions, namely:

(1) Along the east-west direction of the eddy center, the velocity component $v^{\prime}$ has opposite signs on both sides of the center point, and the magnitude gradually increases with the distance from the center point.

(2) Along the north-south direction of the center of the eddy, the numerical signs of the velocity components $u^{\prime}$ on both sides of the center point are opposite, and the magnitude gradually increases with the distance from the center point. The direction of change considered is consistent with the direction of change of $u^{\prime}$ and $v^{\prime}$.

(3) In the local region of the eddy center, the velocity has the minimum value.

(4) Around the eddy center, the rotation properties of the eddy velocity vector change are consistent.

Among them, $u^{\prime}$ and $v^{\prime}$ mentioned above in the detection eddy method respectively use AVISO's SLA data according to the geostrophic flow equation (as shown in Equations (2) and (3), where $h^{\prime}$ represents SLA, $f$ is the Coriolis parameter and $g$ is the gravitational acceleration) and $u^{\prime}, v^{\prime}$ are the geostrophic velocity anomalies of zonal and meridional currents. Once eddy centers are determined, eddy boundaries can then be calculated.

\subsubsection{Extract the Eddy Boundary}

In this algorithm, the contour of the flow function is used to define the eddy boundary. Because the eddy velocity field has weak divergence, the velocity vector is tangential to the flow function contour, and the tangential velocity of the flow increases along the normal direction, so the eddy boundary is defined as the outermost closed contour around the center point.

\subsubsection{Track the Eddy Lifespan}

After identifying the center of the eddy from the abnormal height data of the entire sea surface, the trajectory of the eddy is determined by comparing the center position in time. The center of the 
eddy at time $t+1$ has the same polarity as the $\mathrm{N} \times \mathrm{N}$ grid point of the center of the eddy at time $\mathrm{t}$. In this way, the eddy center at time $t$ can be connected with the eddy center at time $t+1$. If no contact center point is found at time $t+1$, a larger area $(\mathrm{N}+\mathrm{N} / 2) \times(\mathrm{N}+\mathrm{N} / 2)$ is searched at time $\mathrm{t}+2$. If at $t+2$, the relevant eddy center is still not found, the eddy is considered to die, and the tracking of the eddy's trajectory ends. The size of the eddy search range needs to be carefully quantified in the next step to avoid fragmentation of the eddy trajectory (the continuous eddy trajectory is divided into multiple trajectories). In order to further improve the performance of the algorithm, the AVISO velocity field was linearly interpolated into a $1 / 8$ by $1 / 8$ degree grid before the detection method was applied so that the eddy current velocity field could be extended to more grid points. For details of this tracking method, please refer to Nencioli et al. [46].

Based on SLA data, the EKE can be calculated as follows:

$$
E K E=\frac{1}{2}\left(u^{\prime 2}+v^{\prime 2}\right)
$$

where respectively, $u^{\prime}$ and $v^{\prime}$ are the geostrophic velocity anomalies of zonal and meridional currents. Individually, they can be calculated as follows:

$$
\begin{gathered}
u^{\prime}=-\frac{g}{f}\left(\frac{\partial h^{\prime}}{\partial y}\right) \\
v^{\prime}=\frac{g}{f}\left(\frac{\partial h^{\prime}}{\partial x}\right)
\end{gathered}
$$

where $h^{\prime}$ is SLA, $g$ and $f$ are the gravitational acceleration and Coriolis parameters, respectively.

Similarly, vorticity and strain rate used to characterize the motion state of the eddy can be expressed as follows:

$$
\begin{gathered}
\xi=\frac{\partial v^{\prime}}{\partial x}-\frac{\partial u^{\prime}}{\partial y} \\
S_{r}=\sqrt{\left(\frac{\partial u^{\prime}}{\partial x}-\frac{\partial v^{\prime}}{\partial y}\right)^{2}+\left(\frac{\partial v^{\prime}}{\partial x}+\frac{\partial u^{\prime}}{\partial y}\right)^{2}}
\end{gathered}
$$

where $u^{\prime}$ and $v^{\prime}$ are the same as above. In Formula (5), the first item under the root sign represents the tensile deformation rate, and the latter item indicates the shear deformation rate.

\section{Results}

\subsection{Eddy Statistical Analysis}

There are two ways to define the number of eddies in a given area: the Lagrangian eddy-counting method: one whole life of sequent eddies is considered as one eddy; and the Eulerian eddy-counting method: eddy number depends on how many eddy are identified from each snapshot. Over the 26-year period from 1993 to 2018, the number of eddies based on different eddy-counting methods is shown in Table 1. Here, CEs counted by the Lagrangian and Eulerian methods are all excess AEs, accounting for about $1.02 \%$ and $1.08 \%$ of AEs, respectively. The ratios obtained by the two methods are similar. Taking into account the relative error of SLA measurements, in order to ensure data accuracy, eddies with a lifespan of longer than or equal to four weeks are screened for subsequent research and analysis. Again, the ratio of opposite polarity eddies using both eddy-counting methods are roughly equivalent, although with CEs accounting for 1.11\% more of AEs. A 10 November 2016 snapshot of eddies detected in the BOB based on SLA data as provided by AVISO is presented in Figure 3. For CEs, blue lines demarcate eddy boundaries and the blue asterisks represent eddy centers. Identically for AEs, red lines demarcate eddy boundaries and red asterisks represent eddy centers. The background vector field corresponds to the geostrophic velocity anomalies. As can be observed in Figure 3, eddy radii close to coastlines are small, gradually increasing further away from land. More eddies appear in 
areas characterized by large current velocities and complex transitional flow directions such as the East Indian Coastal Current (EICC). All subsequent eddy features are analyzed based on this dataset.

Table 1. Eddy number table counted by different methods.

\begin{tabular}{ccccc}
\hline Lifespan (Days) & Eddy-Counting Methods & Eddy & CE & AE \\
\hline \multirow{2}{*}{ lifespan $\geq 7$} & Lagrangian & 11,730 & 5924 & 5788 \\
\cline { 2 - 5 } & Eulerian & 287,365 & 149,229 & 138,136 \\
\hline \multirow{2}{*}{ lifespan $\geq 28$} & Lagrangian & 2358 & 1237 & 1121 \\
\cline { 2 - 4 } & Eulerian & 110,524 & 58,037 & 52,487 \\
\hline
\end{tabular}

CE (cyclonic eddy); AE (anticyclonic eddy).

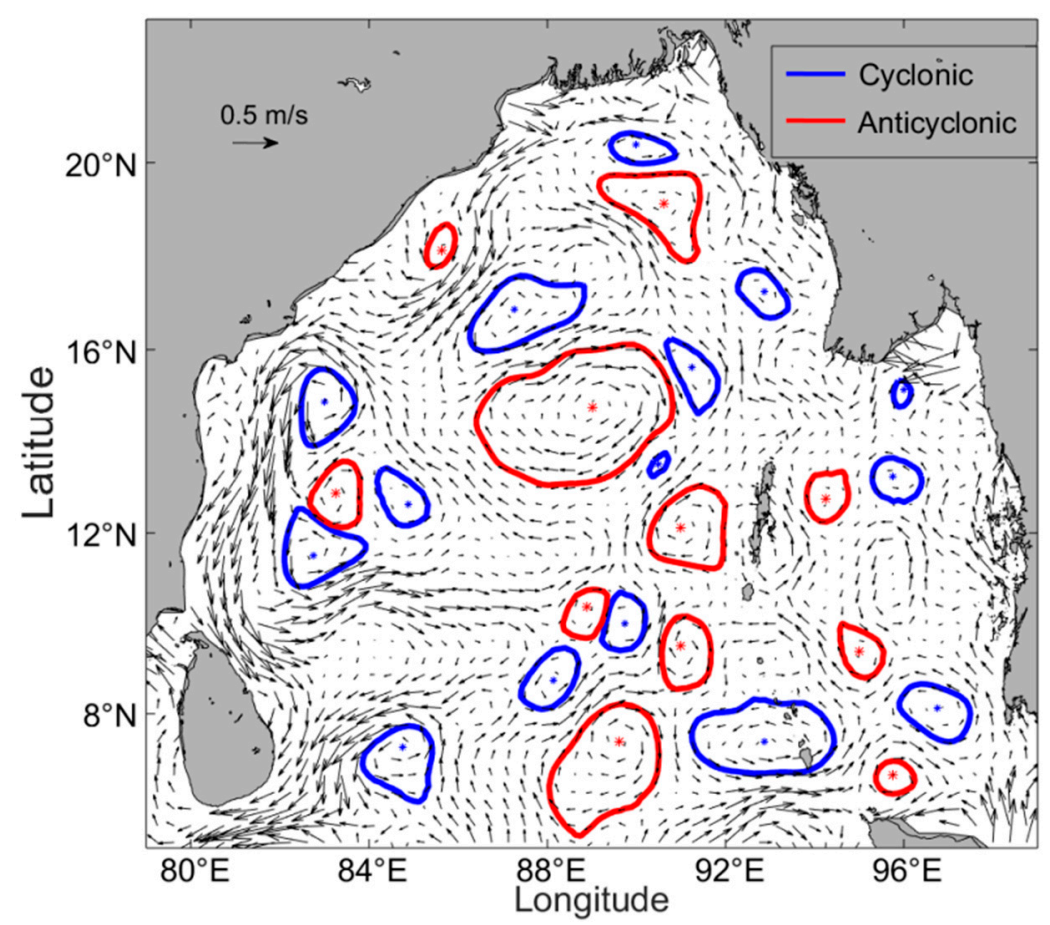

Figure 3. Snapshot of eddy distribution on 10 November 2016. Blue (red) asterisks and circles represent the centers and boundary curves of CEs (AEs). Vectors correspond to surface geostrophic velocity anomalies.

EKE is an important dynamic factor that characterizes the activity of internal ocean variabilities and its spatial distribution is conducive to an analysis of energy sources and sinks. The larger region of EKE had more active eddies [53]. In the multi-year average EKE distribution map presented in Figure $4 \mathrm{a}$, it can be observed that on the BOB west coast, central and western parts of the Andaman Sea, and southeast of Sri Lanka, EKE reaches a maximum of $2500 \mathrm{~cm}^{2} / \mathrm{s}^{2}$. Excluding the north BOB enclosed by $15-20^{\circ} \mathrm{N}, 91-95^{\circ} \mathrm{E}$, high EKE values are restricted along the continental shelf, due to the presence of the EICC, consistent with previous observations [23,44]. Through reference to Figure $2 \mathrm{a}, \mathrm{b}$, it can be shown that seasonal circulation is, to a certain degree, correlated with EKE distribution as areas defined by strong current velocities are also characterized by high EKE values. In Figure $4 b$, weighted average interannual EKE evolution is presented. There, the value of EKE hovers at approximately $500-700 \mathrm{~cm}^{2} / \mathrm{s}^{2}$, of which the years 1993,1998 (highest at $681 \mathrm{~cm}^{2} / \mathrm{s}^{2}$ ), 2002, 2005, 2010, 2014-2016 are relatively strong in comparison. By contrast, the years 1994, 1995, 2000, 2001, 2008, 2009, 2011, 2017 and 2018 are relatively weak. Notably, high values of EKE observe in 1998, 2002, 2014 and 2016 occur concurrently with the onset of El Niño, with 1998 being the strongest year of 
El Niño on record since 1950 [54]. Correspondingly, the years 1995, 2000, and 2007-2009 where EKE values are small, are La Niña years, thus suggesting that EKE interannual variability may be linked to El Niño and La Niña events. Figure 4c gives the monthly EKE. EKE is highest during the spring (MAM) and October, with the highest value observed in May at approximately $590 \mathrm{~cm}^{2} / \mathrm{s}^{2}$. EKE in September and winter (DJF) are at the lowest values throughout the year.
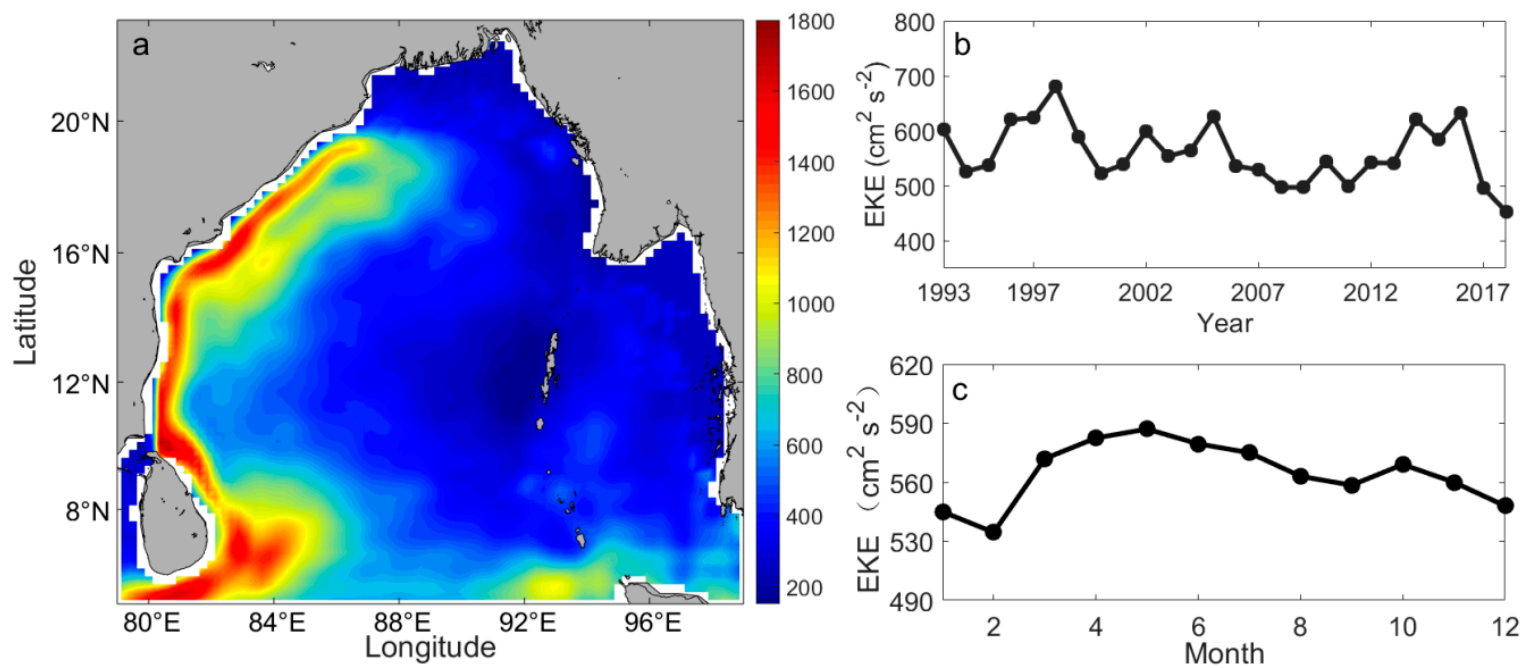

Figure 4. (a) Spatial distribution of the multi-year average eddy kinetic energy (EKE) over the period of 1993-2018; (b) the interannual variation of area-averaged EKE; (c) the seasonal variation of the area-averaged EKE (unit: $\mathrm{cm}^{2} / \mathrm{s}^{2}$ ).

\subsubsection{Eddy Spatiotemporal Distributions, Sizes and Lifespan}

For those eddies with lifespans of greater than 4 weeks, characteristic analyses were performed to determine their distributions and sizes. In total, the number of eddies per year was observed at approximately 4200, and the interannual variation in eddy number is shown in Figure 5. On the whole, excluding 1994, 1997, and 2017, the proportion of CEs is greater than AEs in all other years. The number of AEs account for approximately 89\% of the total number of CEs. In particular, in 1995, 1998, 1999, 2008 and 2011 the number of CEs are significantly higher than that of AEs. Although there is no obvious observable trend in the interannual change in the number of eddies, a small high-frequency periodic change is observed at about 3-5 years, leading to a wave-like pattern. For example, the 1993-1997 and the 1997-2002 periods are the first and second waves, with the trend continuing in the 3-5-year cycle. In Figure 5b, a gradual upward trend in total eddy numbers can be observed with the largest number of eddies appearing in spring, followed by October-December, with the least in summer (JJA). Excluding January, all other months contain more CEs than AEs and this is even more pronounced in spring and autumn (SON).

In order to understand the distribution of eddies in different regions more clearly, the study area is divided into $1^{\circ} \times 1^{\circ}$ bins, and shown in Figure 6; all eddies in each grid point based on the eddy center at each moment are screened out (58,037 CEs and 52,487 AEs). From both Figure 6a,b which depict the number of CEs and AEs, respectively, it can be observed that the western and northern central parts of the BOB, east of Sri Lanka and the Andaman Sea, are highly populated by eddies. In each subregion, statistics indicate that there are more than 900 CEs or AEs in each bin, but the trend of there being more CEs than AEs remains, mainly concentrated in the mid-Andaman Sea, and west BOB. With reference to Figure 4, the overall distribution of either polarity eddies is similar to that of EKE, with some areas of overlapping high eddy density and EKE values. 

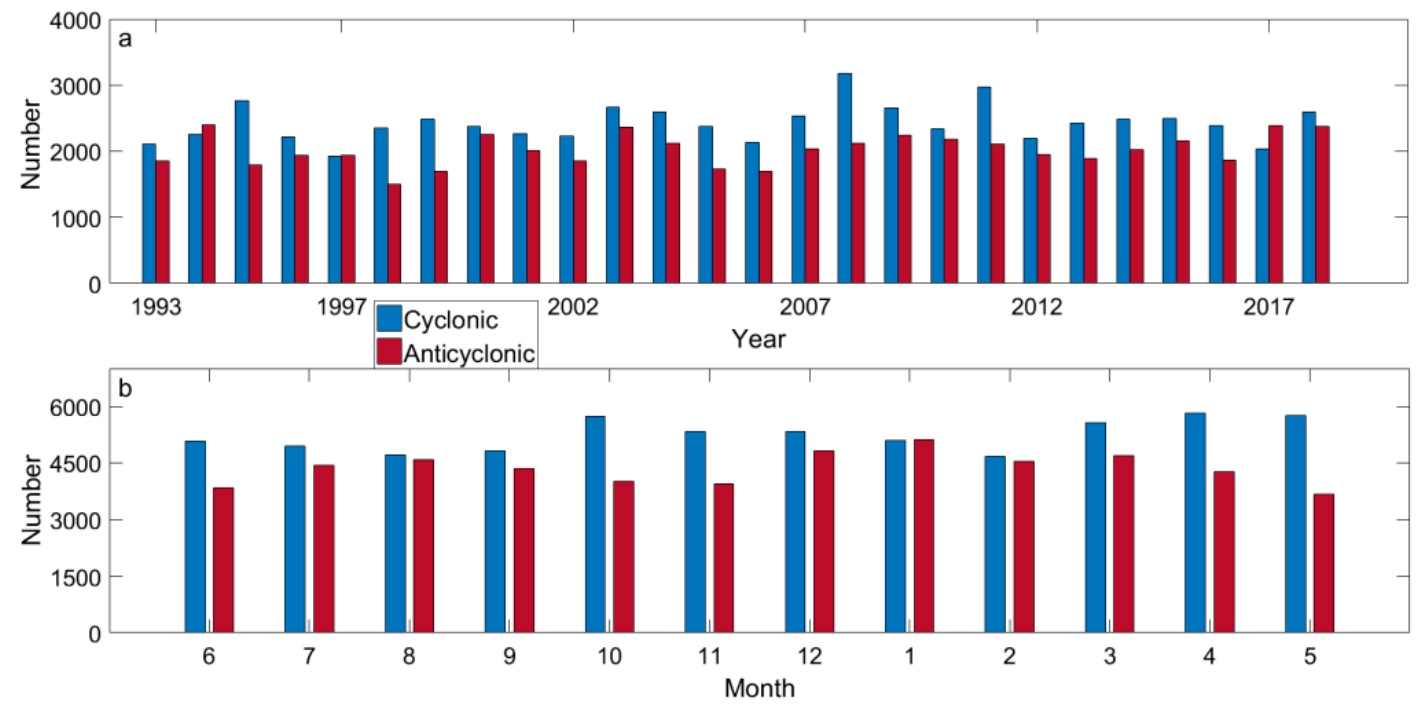

Figure 5. (a) The interannual variation in eddy numbers. (b) The seasonal variation in eddy numbers.
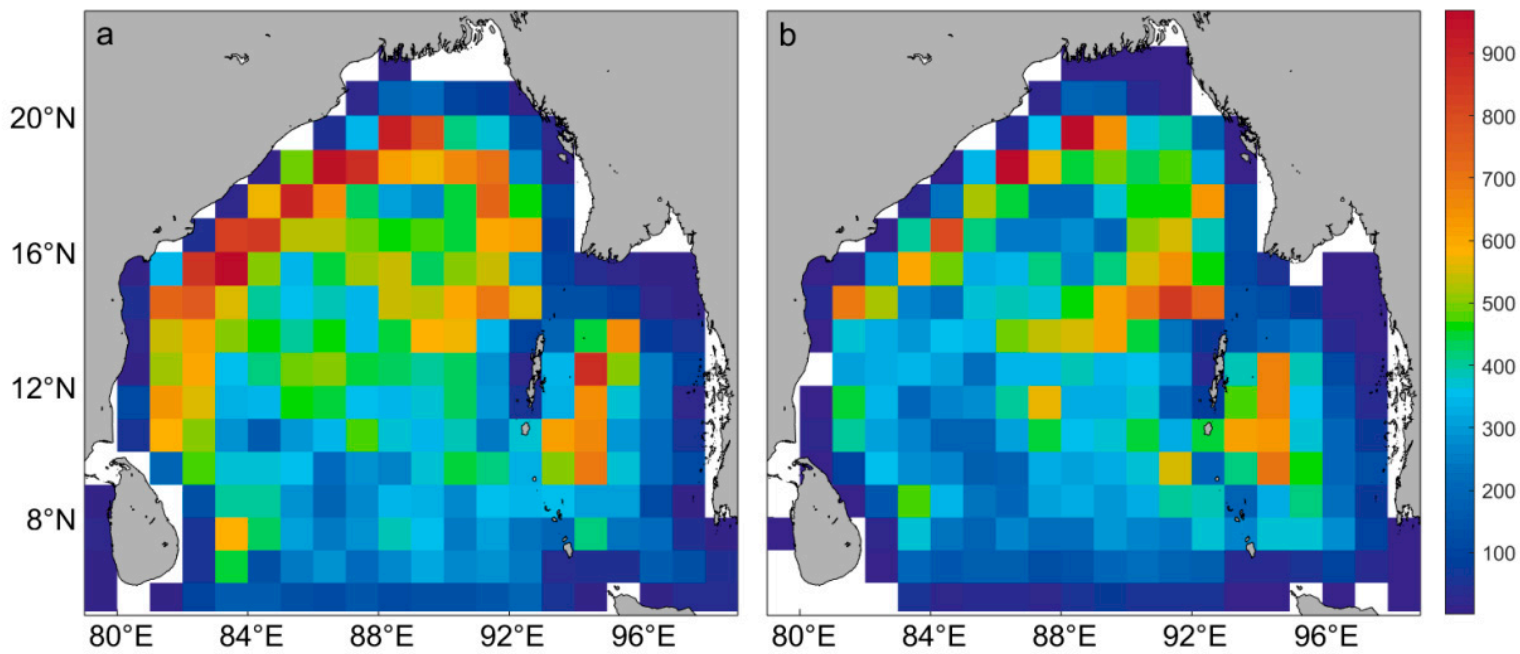

Figure 6. Spatial distribution of average eddy number (lifetime $\geq 4$ weeks) over $1^{\circ} \times 1^{\circ}$ bins for CEs (a) and AEs (b).

As compared to those areas, the number of eddies in coastal zones and near the equator is relatively small. For these two factors, low eddy densities could be due to blockage by land and the reduction of the strength of the Coriolis force with decreasing distance to the equator. Because of this second observation, the paper have restricted its study to regions above $5^{\circ} \mathrm{N}$ as the Coriolis force decreases with decreasing distance to the equator, eventually becoming zero at the equator.

Figure 7 presents the number of eddies based on their lifespans ( $\geq 4$ weeks). In Figure $7 \mathrm{a}$, it can be readily observed that on average, a given CE may live for approximately 7 weeks, while an AE may live for approximately 6 weeks. An average of 93 eddies are generated each year. Excluding those eddies that last for only 4 weeks; the number of CEs is roughly equivalent to the number of AEs. Of more than $88 \%$ of eddies that last for up to than 10 weeks, $4 \%$ can live beyond 17 weeks, with the most extreme lasting for up to 40 weeks. Of all eddies that last for more than 10 weeks, 198 are CEs and 138 are AEs, providing additional evidence that greater numbers of CEs last longer than AEs. Eddy radii statistics are presented in Figure $7 \mathrm{~b}$. It can be observed that eddies possessing radii of $100 \mathrm{~km}$ to $120 \mathrm{~km}$ accounts for $~ 80 \%$ of the total number of eddies $(50,511$ CEs and 41,843 AEs, following a Gaussian distribution), with the highest number of eddies possessing radii of $110 \mathrm{~km}$. CEs, 
on average, have radii of $\sim 111 \mathrm{~km}$, with AEs being slightly smaller at $\sim 110 \mathrm{~km}$. This is followed by eddies possessing radii of $90 \mathrm{~km}$ to $100 \mathrm{~km}$ and $120 \mathrm{~km}$ to $130 \mathrm{~km}$, which accounts for $15.6 \%$ of the total. Just over $1.2 \%$ eddies have radii greater than $150 \mathrm{~km}$. Notably, within the same radii ranges, for example the $90-100 \mathrm{~km}$ and $140-160 \mathrm{~km}$ ranges, symmetry between AEs and CEs is again broken as regarding the number of AEs accounting for $1.09 \%$ and $1.13 \%$ of the number of CEs, respectively.
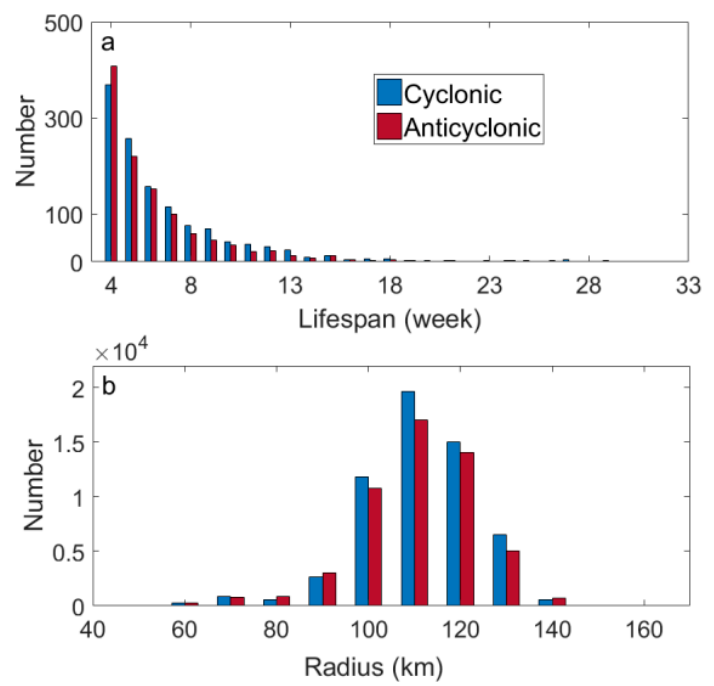
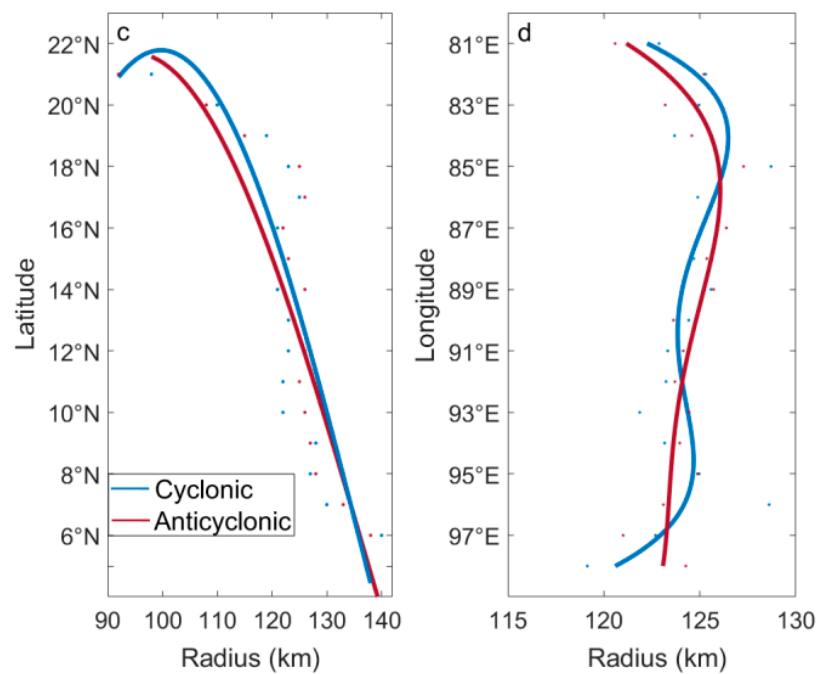

Figure 7. Eddy lifespan (lifetime $\geq 4$ weeks) (a), radii (b) statistics, with change of radii by latitude (c) and longitude (d). Among them, in (c) and (d) the points represent the average radius of the eddy at each latitude (longitude), and the line represents the exponential regression result based on the corresponding point data.

In Figure $7 c, d$, eddy radii variability with latitude and longitude are presented. An exponential regression is applied to the scatting plot of the average radii of the eddy at different latitudes and longitudes, that is, a smooth trend can be obtained for the relationship of the eddy radii with varying with latitude and longitude. In Figure 7c, eddy radii generally decrease with increases in latitude where from $5^{\circ} \mathrm{N}$ to $18^{\circ} \mathrm{N}, \mathrm{CE}$ and $\mathrm{AE}$ radii differ minutely, and range between $110 \mathrm{~km}$ and $130 \mathrm{~km}$ before decreasing sharply below $19^{\circ} \mathrm{N}$ and the difference between $\mathrm{CE}$ and $\mathrm{AE}$ radii sizes increases favoring CEs. The above trend can be verified through understanding the relationship between the buoyancy frequency and the Rossby radius of deformation. In a stable, stratified ocean, pressure gradually increases with depth before experiencing a sharp jump in the thermocline, before returning to a gradual development path in a small range. From the perspective of buoyancy frequency, as the depth increases, the buoyancy frequency first increases before decreasing rapidly, reaching a local maximum at the thermocline. Simultaneously, when combined with the first baroclinic Rossby radius, it is a very important scale parameter in ocean circulation studies which can describe fluid motion on a rotating Earth and is related to mesoscale eddies. Based on an analysis conducted by Chen et al. [21] where it is suggested that changes in mesoscale eddy radii with latitude is roughly consistent with the Rossby radius of deformation, and with reference to its equation, the changes in eddy radii with latitude observed in this paper are consistent with the literature. By contrast, changes in eddy radius with longitude are not as noticeable and eddy radii are mainly concentrated in the $120 \mathrm{~km}$ to $128 \mathrm{~km}$ range. The overall trend is relatively smooth, with a small increase in radii from west to east. As compared with AEs, CEs experience greater changes in radii and while radii also increase with increasing distance from land, this change is slight at only $2 \mathrm{~km}$ to $3 \mathrm{~km}$. 


\subsubsection{Eddy Vorticity, Strain, and Evolution}

Vorticity and EKE are usually regarded as physical quantities closely related to the degree of eddy activity, which can characterize the strength of an eddy. Vorticity characterizes the rotational characteristics of the velocity field and represents the degree of eddy baroclinicity. Theoretically, the maximum value of the vorticity of the eddy is at its center, gradually decreasing by increasing radial distance from the center, and is zero at the boundary. Therefore, the maximum value of the vorticity is taken as the relative vorticity of the eddy subsequent estimations. Identical to the above studies, to analyze values (absolute) of average normalized relative vorticity (NRV) shown in Figure 8a,b, the study area is first divided into $1^{\circ} \times 1^{\circ}$ bins. Within the $\mathrm{BOB}$, the geographical distribution of $\mathrm{CE}$ and $\mathrm{AE}$ average NRV is generally identical, with the overall distribution similar to that of EKE. That is, high values (absolute) of NRV are mostly concentrated in the west and the south of the BOB, Andaman Sea and near Sri Lanka. The values are mostly between 0.12 and 0.3 , and the maximum value can reach 0.7. Values (absolute) of NRV are higher in the west as compared to the east and this may be related to sites of eddy generation or westward propagation. Southeast of Sri Lanka, a region characterized by relatively large (absolute) vorticity values $(>0.5)$ can be observed, serving as a nursery for the so-called Sri Lankan and southwest eddies [55]. Comparatively lower values of absolute vorticity can be observed in the northeastern part of the BOB and western coasts of the Andaman Sea, reaching as low as 0.0018 .
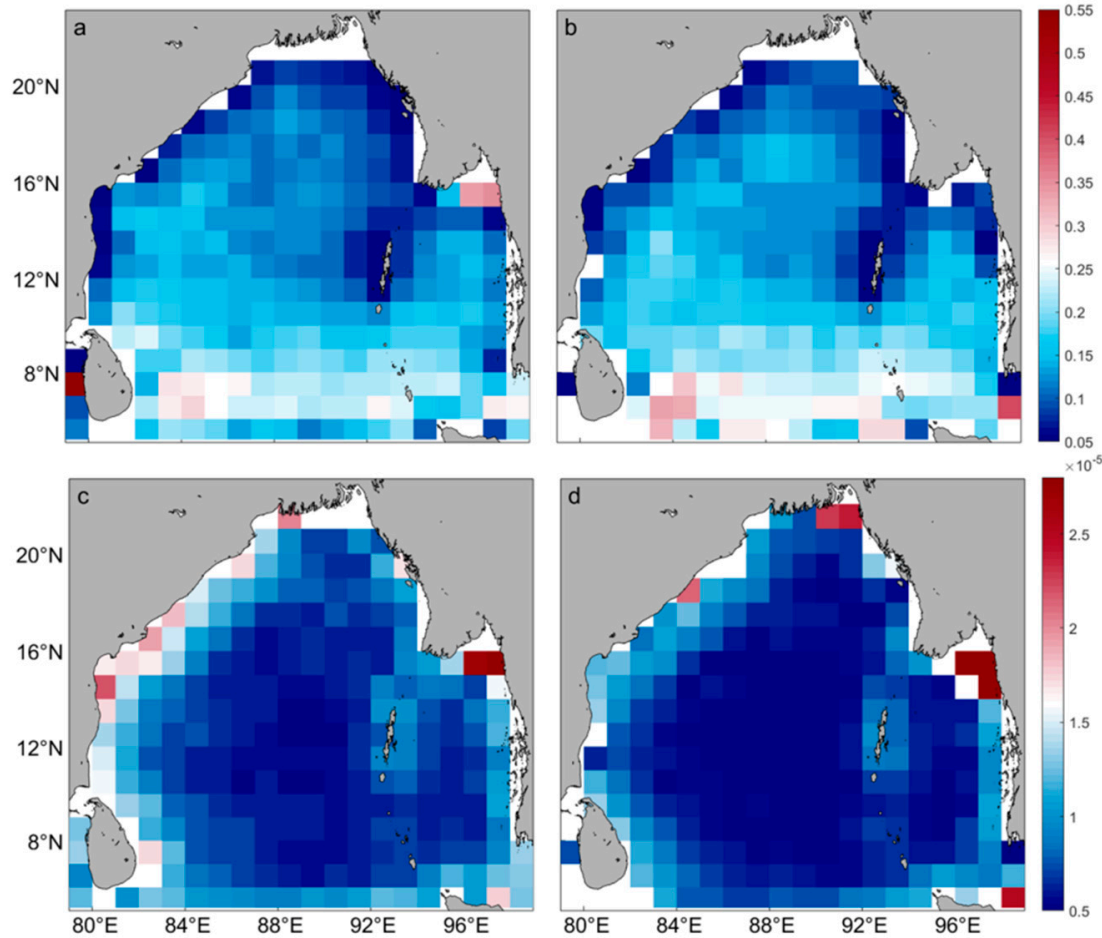

Figure 8. Spatial distribution of absolute values of normalized eddy relative vorticity (divided by local Coriolis parameter for (a) CEs and (b) AEs. Spatial distribution of strain rate for (c) CEs and (d) AEs (unit: $\mathrm{s}^{-1}$ ).

Another physical quantity that characterizes the state of eddy motion is the strain rate, which is also called the deformation rate, that is, the rate of change of strain with time. In Figure $8 c, d$, spatial maps of eddy relative average strain (or deformation) rate is shown. Regardless of eddy polarity, vorticity strain rates are largely symmetrical, although AE strain rates are marginally higher than CE strain rates. This result is opposite to the overall eddy NRV distributions. Specifically, eastern and western coastal boundaries and the southern $\mathrm{BOB}$ are areas with high strain rates, and in 
the central BOB, topographic obstruction and the injection of freshwater along the coast may be responsible for lower eddy strain rates. Maximum and minimum CE strain rates are measured at $3.965 \times 10^{-5} \mathrm{~s}^{-1}$ and $1.736 \times 10^{-6} \mathrm{~s}^{-1}$, respectively. Maximum and minimum AE strain rates are measured at $3.792 \times 10^{-5} \mathrm{~s}^{-1}$ and $1.594 \times 10^{-6} \mathrm{~s}^{-1}$, respectively. It can be observed that the minimum strain rate of either eddy polarity is roughly the same.

In Figure 9, histograms concerning the normalized relative vorticity of CEs and AEs are presented. In Figure 9a, it can be observed that variability trends are skewed and are close to one another. Peaks of both CEs and AEs are 0.14 , the average NRV of CEs is measured at 0.16 and for AEs, and it is measured at -0.15 . When absolute values are used, $C E$ and $A E$ intensities are virtually identical, although the overall number of CEs remains slightly greater than AEs. This is especially the case after absolute vorticity values meet or exceed 0.18 , but when absolute vorticity is less than 0.06 , the number of AEs exceeds that of CEs. In Figure 9b, corresponding strain rates for eddy number variability is given and it can be demonstrated that for both eddy polarities, the strain rate follows a skewed distribution, peaking at $0.5 \times 10^{-5} \mathrm{~s}^{-1}$. Over $76 \%$ of the entire study area is characterized by strain rates of between $0.4 \times 10^{-5} \mathrm{~s}^{-1}$ and $0.9 \times 10^{-5} \mathrm{~s}^{-1}$. Excluding strain rates of $0.3 \times 10^{-5} \mathrm{~s}^{-1}$, the number of CEs is significantly more than that of the AEs. Nearly $0.42 \%$ of eddies possess high strain rates $\left(>15 \times 10^{-5} \mathrm{~s}^{-1}\right)$.
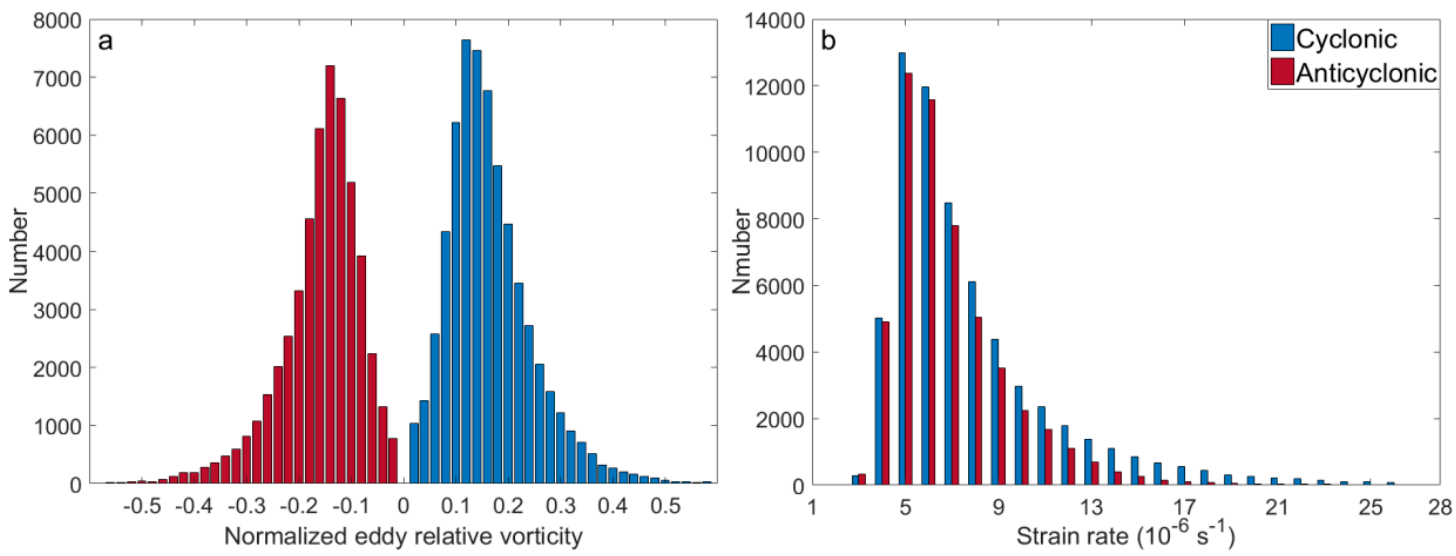

Figure 9. Histograms of (a) normalized eddy relative vorticity (divided by the local Coriolis parameter) and (b) strain rate (unit: $\mathrm{s}^{-1}$ ).

As with any living organism, eddies also go through several stages of life, ranging from birth (i.e., generation), intensification (rapid growth), maturation (adulthood), and dissipation (decay). Each stage can be clearly demarcated by normalized age: generation $(\sim 0-0.1)$, intensification $(\sim 0.1-0.3)$, maturation ( 0.3-0.8), and decay (>0.8). Consequently, eddy parameters such as eddy radius, EKE, strain rates and NRV (i.e., undergoing a second normalization process) throughout an eddy's lifecycle are normalized. Again, 1237 CEs and 1131 AEs with lifespans of greater than four weeks are selected for a statistical analysis. Results are presented in Figure 10 and it can be observed that the normalized eddy radii (Figure 10a), EKE (Figure 10b), and NRV (Figure 10c) all present with the same convex shapes, demonstrating an eddy's lifecycle, regardless of eddy polarity. Strain rate (Figure 10d) is the only outlier, presenting a concave eddy lifecycle shape, thus demonstrating that at an eddy's generation, strain rate first decreases to a minimum at its mature stage where it is most circular, before deforming near its eventual dissipation. During an eddy's birth, regardless of eddy polarity, normalized strain rates are virtually identical but grow increasingly dissimilar as the eddy matures to the point where CEs experience greater levels of deformation than AEs, at 0.6, before inflecting upwards. Generally, similarity in variability between the four parameters is at its greatest during the eddy formation and dissipation stages, while during intensification and maturation stages, these parameters are left relatively unchanged. 


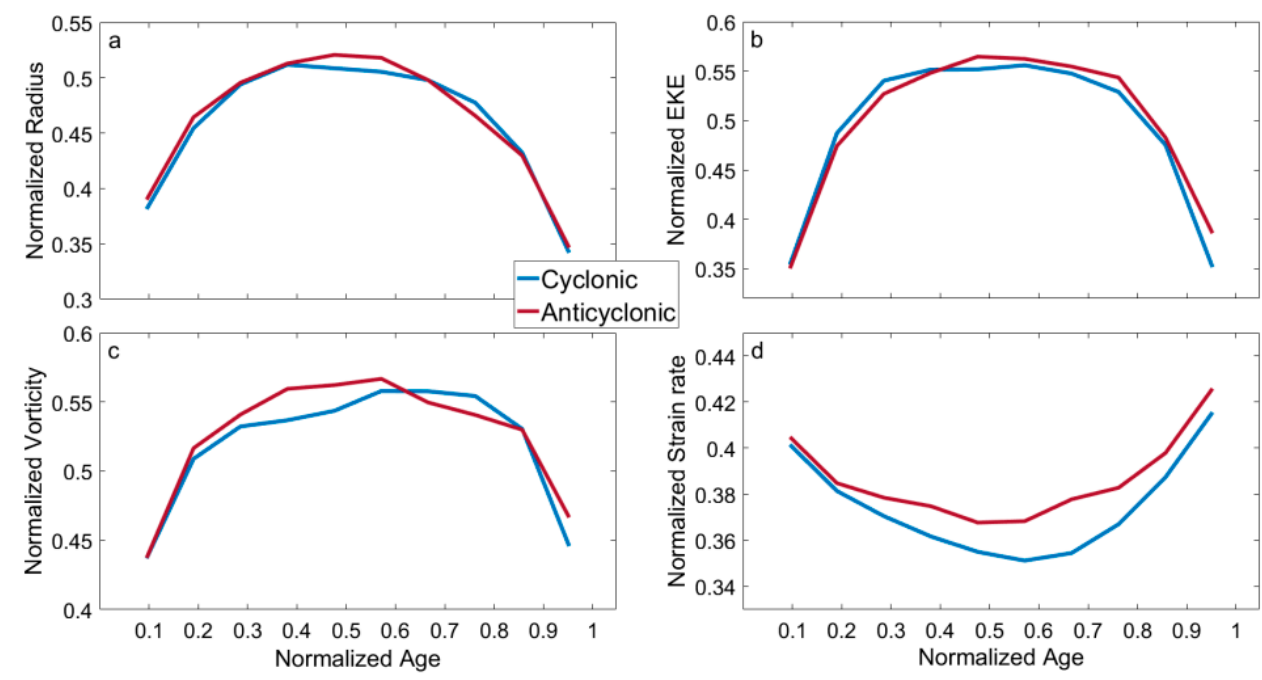

Figure 10. Time evolution of the mean normalized (a) radii, (b) eddy kinetic energy, (c) relative vorticity and (d) strain rate.

\subsubsection{Eddy Generation and Dissipation}

For a clearer understanding of the generation and dissipation of eddies, we define eddy formation and dissipation times as the time series generated through the first and last records of a detected eddy. Dates and centers at the formation of the eddy are then recorded, allowing for both records of eddy formation and dissipation to be studied through the identification of eddy nurseries and graveyards. Similar to the above sub-studies, the study area is again divided into $1^{\circ} \times 1^{\circ}$ bins and only eddies with lifespans exceeding four weeks are used. In Figure 11 it can be observed that the distribution of CEs and AEs is relatively similar, and they are mostly born (eddy nurseries) in the Andaman Sea, central $\left(\sim 89^{\circ} \mathrm{E}-94^{\circ} \mathrm{E}\right)$ and northern (above $\left.12^{\circ} \mathrm{N}\right) \mathrm{BOB}$, consistent with previous observations $[21,24,25]$. Although more of the the central and western boundary of the BOB produces more AEs than CEs, this observation is reversed in the Andaman Sea where more CEs are produced. In Figure 11c,d, eddy graveyards can be identified in the western $\mathrm{BOB}$ and western Andaman Sea, where the number of CEs is slightly greater than that of AEs, and this may be related to topographic obstruction caused by the present Andaman Islands archipelago. A striped pattern of more and fewer eddies can be observed from west to east, following roughly the same distribution as of more and fewer bands in the number of eddies as EKE from Figure 4a, and eddy vorticity in Figure 8a,b.

Time series of eddy formation and dissipation are presented in Figure 12. As shown, between 1993 and 2018, 1237 CEs and 1121 AEs were formed, and 1229 CEs and 1120 AEs dissipated, leaving a remainder of just $8 \mathrm{CEs}$ and $1 \mathrm{AE}$ in the study area. On an interannual scale (Figure 12a,b), it can be observed that CEs were more numerous than AEs, regardless of either eddy formation or dissipation, leading to an average of $47 \mathrm{CEs}$ and $43 \mathrm{AEs}$ generated per year. CEs were more populous than AEs in 1995, 1999, 2000, 2003, 2009, 2011, and 2014, but lost numerical superiority in 1997, 2002, 2004, 2006, 2010, and 2015. For AEs, there were more in 1994, 2000, 2003, 2007, 2010, 2012, 2014 and 2017, and fewer in 1998, 2002, 2006, 2011, 2013 and 2018. In terms of the trend of eddy dissipation, both CEs and AEs showed slight fluctuations as compared with eddy formation. Previous studies have pointed out that the interannual distribution of eddies may be related to the monsoon $[21,56]$. On seasonal scales (Figure 12c,d), the inverse to the interannual trend was observed. Excluding summer, AEs are more numerous throughout the year than CEs, with the maximum number occurring in spring (March) and autumn (October), and the minimum in the summer (June). AEs are produced more prodigiously in the summer (August) and winter (December), with the smallest amounts observed in the autumn (September and October). CE dissipation and generation trends were similar. In April, May, June and October, November, and December, there are significantly more CEs than 
AEs, but in January, March, July, and September, this trend is reversed with more AEs than CEs. Seasonal differences between the two eddy polarities may be due to local monsoon and circulation patterns, necessitating further investigations.
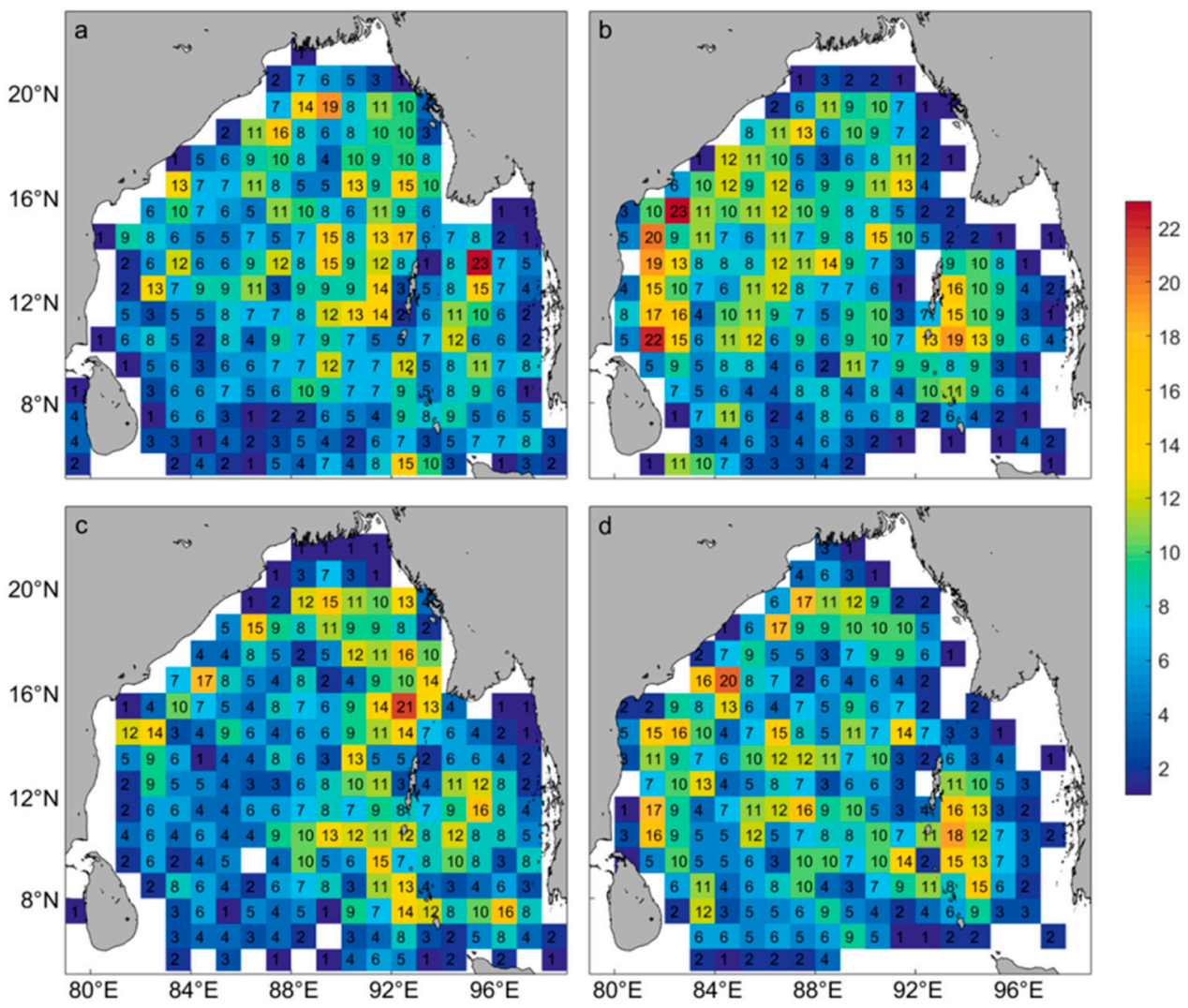

Figure 11. Spatial distributions of eddy generation number for CEs (a) and AEs (c) and dissipation number for CEs (b) and AEs (d) (lifespan $\geq$ four weeks) over $1^{\circ} \times 1^{\circ}$ bins.
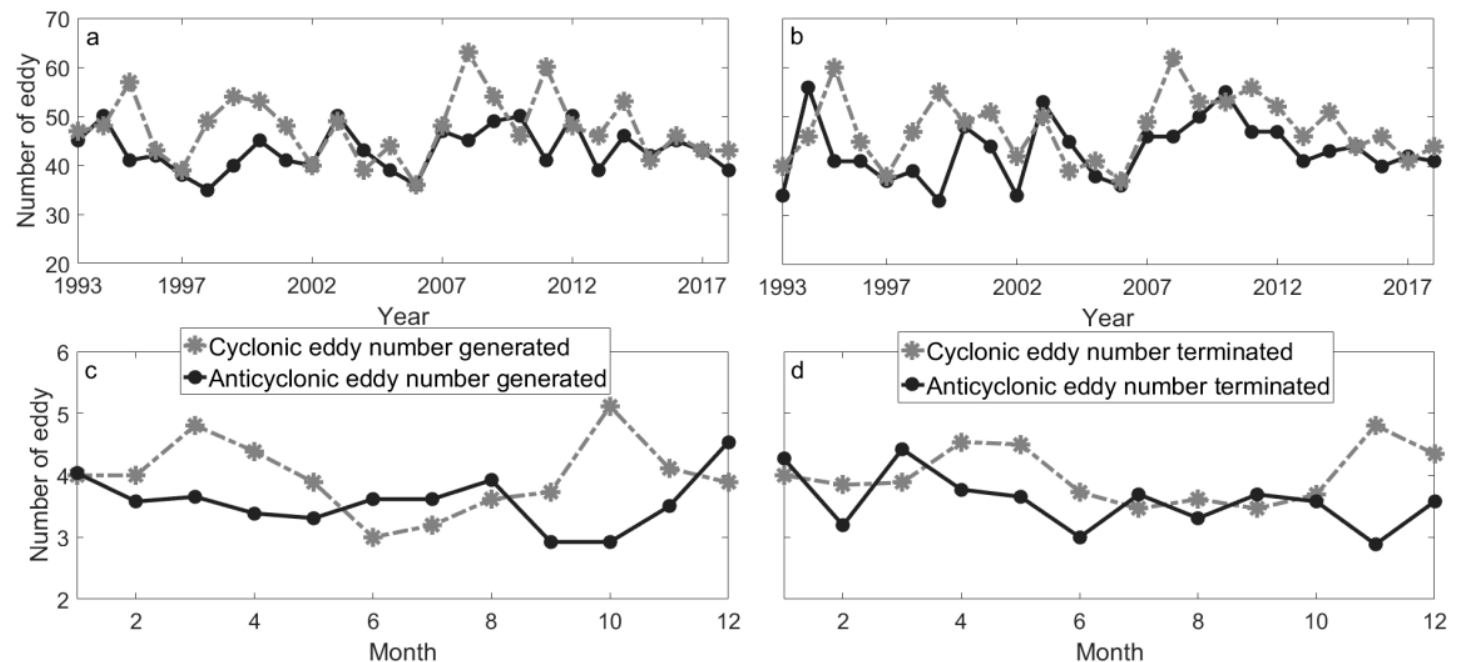

Figure 12. The interannual variation of the number of (a) generated and (b) dissipated eddies. The seasonal variation of the number of (c) generated and (d) dissipated eddies. Gray lines identify CEs, while black lines demarcate AEs. 


\subsubsection{Eddy Movement and Propagation}

Mesoscale eddy movement can alter seawater properties through the transmission of mass, energy, and momentum [10]. Eddies with lifespans of greater than 18 weeks were used as above and their trajectories are presented in Figure 13a,b. Among them, the position changes of the center of the eddy during its life cycle are defined as the movement trajectory of the eddy. The position of the eddy center on the first day is the origin of the eddy, and the position of the eddy center on the last day is the end of the eddy, accordingly. Approximately $91 \%$ of all eddies, regardless of polarity, propagate west/southwestward to occupy the entirety of the BOB, being mostly concentrated in the Andaman Sea and the BOB's western and central regions $\left(86-93^{\circ} \mathrm{E}, 13-16^{\circ} \mathrm{N}\right)$. Most of the remaining eddies (CEs and AEs in roughly equal amounts) were found to propagate along southwestern paths before CEs began to predominantly inhabit the northwestern and southwestern coastal areas. AEs became dominant in the southeastern and central BOB. General eddy trajectories roughly aligned with the distribution of EKE (Figure 4a). Eastward propagating eddies accounted for approximately $7 \%$ of the total and were scattered around the EICC, near the Andaman Islands and eastern Sri Lanka. Congruent with the observations of Cui et al. [23], this study found that most eddies in the BOB propagated either along west- or southward trajectories.
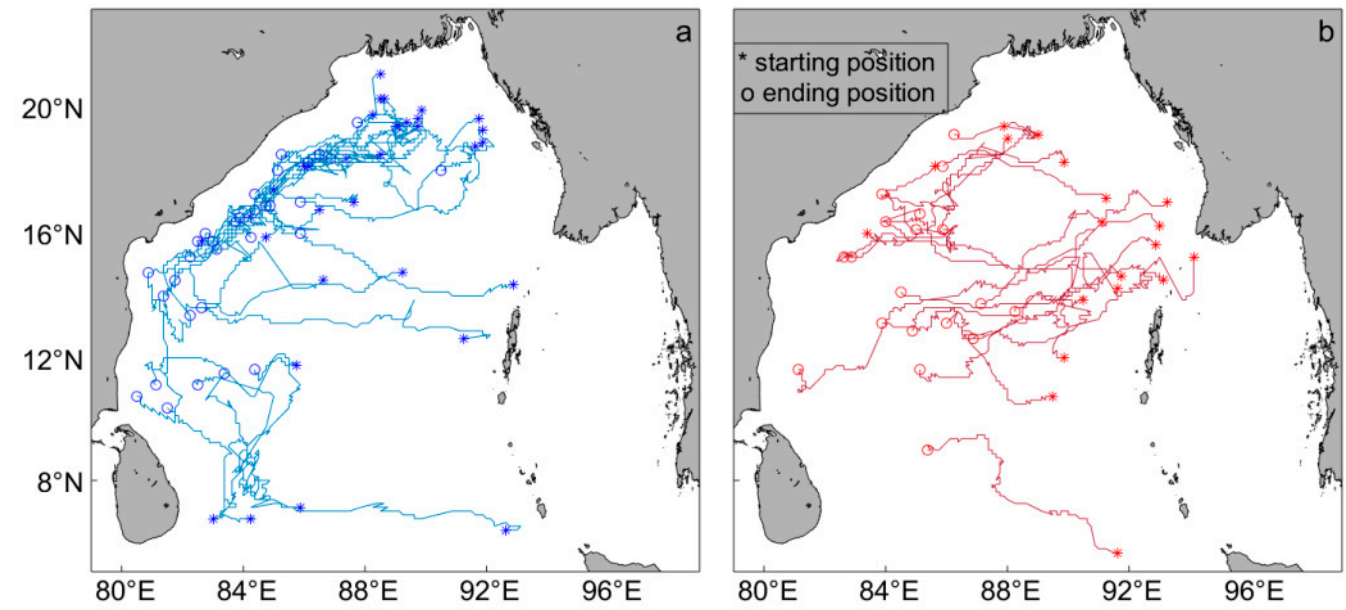

Figure 13. The propagation trajectories of the (a) CEs and (b) AEs with lifespans of greater than 18 weeks. The asterisk indicates the starting positions of an eddy track, and the circle is the ending positions.

With reference to Figure $8 \mathrm{a}, \mathrm{b}$, it can be confirmed that there is a relationship between high vorticity in the western $\mathrm{BOB}$ and eddy propagation. It is suggested that eddy propagation direction may be related to factors such as the local monsoon, the $\beta$-effect, and convection. Westward and southward velocities averaged over $1^{\circ}$ zonal and meridional bands are presented in Figure 14. Westward/southward velocities are defined as positive. In Figure 14a,b, it can be observed that regardless of latitude or longitude, most eddies propagate westwards but, dependent on latitude and longitude, their propagation speeds are the inverse of one another. Westward propagating eddy velocities gradually decrease with increasing latitude, reaching a maximum of $10.27 \mathrm{~cm} / \mathrm{s}$ and a minimum of $1.57 \mathrm{~cm} / \mathrm{s}$. While this change in velocity is similar between CEs and AEs, the average propagation velocity of AEs is marginally greater than CEs. With increases in longitude, westward propagating eddy velocities gradually increase. Average propagation speeds of CEs and AEs are measured at $4.49 \mathrm{~cm} / \mathrm{s}$ and $5.12 \mathrm{~cm} / \mathrm{s}$ respectively, while both rapidly accelerated at approximately $94^{\circ} \mathrm{E}$. It can also be noted that $\mathrm{AE}$ acceleration is of a greater magnitude than $\mathrm{CE}$ acceleration. In low latitudes (south of $12^{\circ} \mathrm{N}$ ), eddies mainly propagate northwards and as the latitude increases, velocities gradually decrease (Figure $14 \mathrm{c}$ ). North of $12^{\circ} \mathrm{N}$, by contrast, eddies mainly propagate southward and accelerate, which may be due to the background current fields, coastal winds, equatorial sea dynamics and external forcing, where for example, countercurrents could be encountered. 

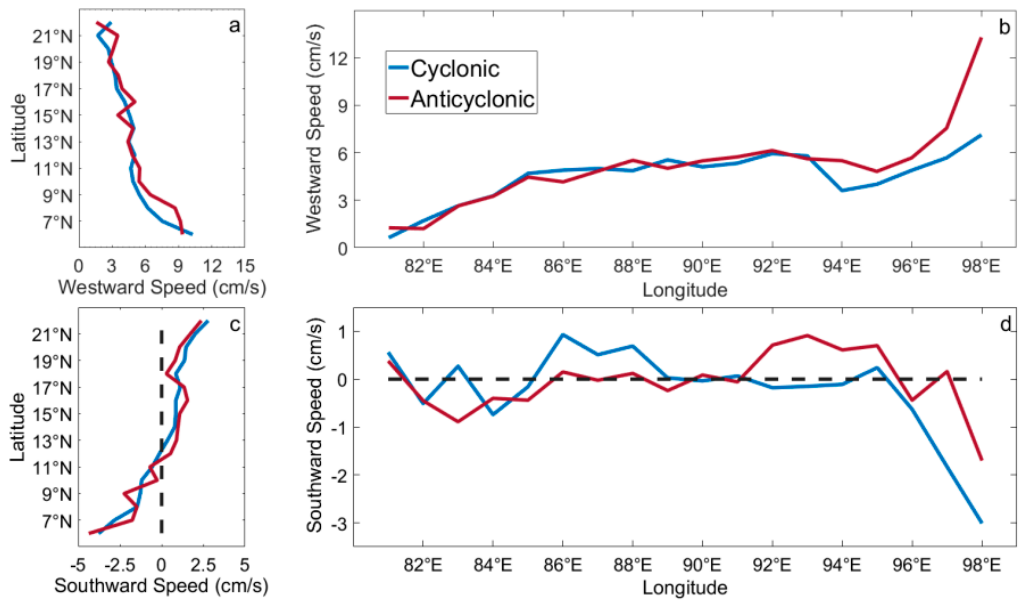

Figure 14. Zonal and meridional average propagation speeds of eddies. Westward speed variation with (a) latitude and (b) longitude. Southward speed variation with (c) latitude and (d) longitude. The positive values indicate the westward and southward speeds (unit: $\mathrm{cm} / \mathrm{s}$ ). (The dotted line indicates that the speed is $0 \mathrm{~cm} / \mathrm{s}$ ).

Inside the BOB, eddy propagation directions change little with longitude, but abruptly change, experiencing rapid propagation velocity reductions near the coast at $96^{\circ} \mathrm{E}$. In Figure $14 \mathrm{~d}$, the meridional changes in eddy southward propagation from $85^{\circ} \mathrm{E}$ to $95^{\circ} \mathrm{E}$ are shown, with CEs and AEs presenting alternating patterns $90^{\circ} \mathrm{E}$. West of $90^{\circ} \mathrm{E}, \mathrm{CEs}$ propagate southwards with large propagation velocities while $\mathrm{AE}$ velocities are close to zero. East of $90^{\circ} \mathrm{E}$, the inverse is true where AEs propagate southwards with large propagation velocities while $\mathrm{CE}$ velocities approach zero. East of $95^{\circ} \mathrm{E}$, eddies begin to propagate northwards at lower velocities. Referencing the generation and dissipation of eddies in Figure 11, it can be ascertained that eddy propagation trajectories and velocities determine that most eddies dissipate on the $\mathrm{BOB}$ western boundary. A global study of eddy propagation conducted by Chelton et al. [8] suggests that due to the $\beta$-effect, CEs largely move polewards, and AEs move equatorward. Sang et al. [57], however, found that eddies on the leeward side of the Canary Islands all moved southwest, demonstrating that in different regions, eddy movement was also different, and was related to local environmental conditions. The results of this study indicated that most BOB eddies move southwestwards. In addition to the $\beta$-effect, eddies are also influenced by other factors such as local oceanic circulation, monsoons, and the driving effect of the EICC.

\subsection{Eddy Impact on Temperature/Salinity (T/S)}

The previous eddy statistics are all based on two-dimensional analyses of mesoscale eddies based on sea surface height anomaly data. To study the relative characteristics of eddies at depth, i.e., the three-dimensional vertical characteristics, Argo profiling floats were used to explore the influence of different eddy polarities on the vertical structure of upper ocean T/S. Based on 26 years (1999-2018) of Argo data captured by 57,055 profilers, a total of 15,988 CEs and 15,652 AEs were identified. Of these, 9316 CEs and 8579 AEs contained at least one Argo profiler. Consequently, there were many profilers in a single eddy which allows for multiple thermohaline (T/S) vertical profiles to be captured. Before analysis, data were quality controlled to ensure that profiles matched eddies, and then data were interpolated onto vertical profiles from 10 to 1000 at $10 \mathrm{~m}$ intervals to obtain the T/S vertical profile. Figure 15 presents changes in T/S within a given eddy. In either CE or $\mathrm{AE}$ case, temperature decreases, and salinity increases gradually with depth. Within the depth range of $150 \mathrm{~m}$ to $250 \mathrm{~m}, \mathrm{~T} / \mathrm{S}$ respectively experience sharp decrease and increases. In this instance, there is little difference in $\mathrm{CE}$ or $\mathrm{AE} \mathrm{T} / \mathrm{S}$ profiles. 

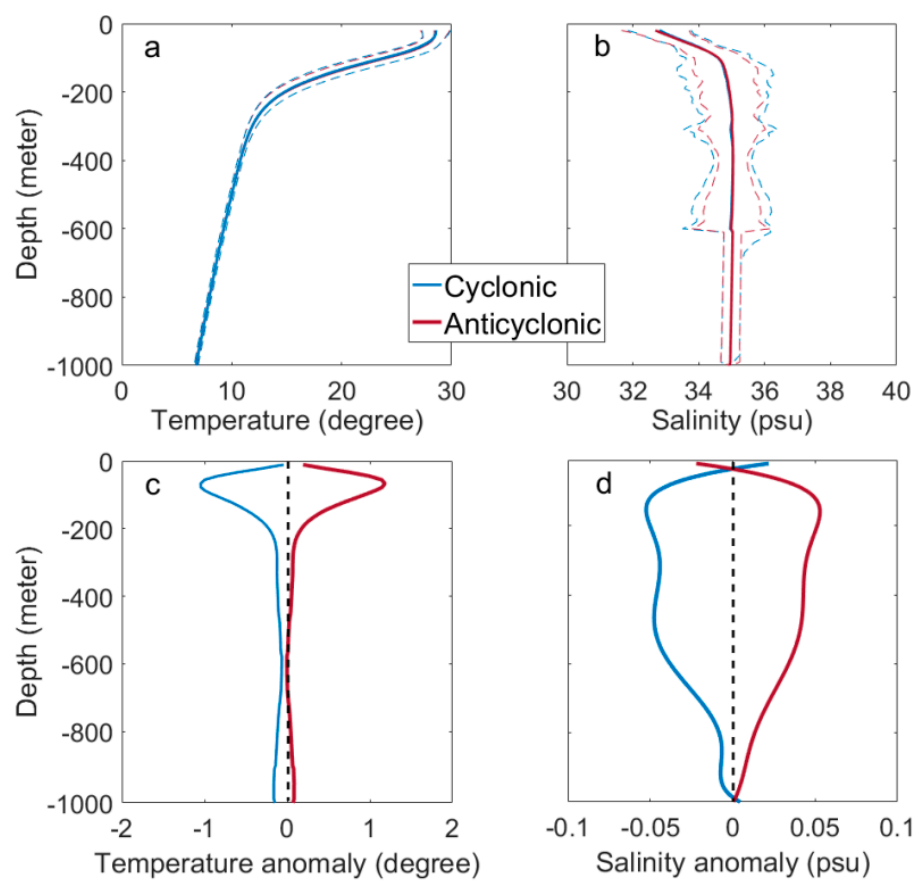

Figure 15. Mean temperature/salinity (T/S) vertical profiles (solid lines) from the Array for Real-Time Geostrophic Oceanography (Argo) data collected within the detected eddies in the study area. Mean (a) $\mathrm{T}$ and (b) S. Anomalies of (c) $\mathrm{T}$ and (d) $\mathrm{S}$ are also provided. Red lines are averages for profiles within AEs; blue lines are averages for profiles within CEs. (Dashed lines indicate the one standard deviation interval).

To further study changes in $\mathrm{T} / \mathrm{S}$ at depth, their vertical anomalies as induced by the eddy are plotted in Figure $15 c, d$, respectively. It can be observed that eddies can affect $T / S$ profiles to a maximum depth of $\sim 900 \mathrm{~m}$. For CEs, negative anomalies in T/S are induced. Symmetrically for AEs, positive anomalies in $\mathrm{T} / \mathrm{S}$ are produced. With increases in depth, absolute values of temperature anomalies of both CEs and AEs first increase, then decrease. For salinity anomalies, two separate increases and decreases occur. In the early stage of eddy evolution, when the eddy is not in the geostrophic balance, the CE (AE) induces upwelling (downwelling) at the center, and high salinity seawater is upwelled towards the surface in the $\mathrm{CE}$, increasing sea surface salinity, and this is inverse for $\mathrm{AE}$, that is, low salinity seawater is downwelled towards the seabed. After the eddy evolution reaches the geostrophic balance, the vertical velocity is almost zero and there is no water vertical transport, but the states caused by the upwelling (downwelling) are maintained. However, it is worth noting that there is basically no change in salinity below 600 , which may be related to missing data or almost similar values. Generally speaking, at approximately $180 \mathrm{~m}$ to $200 \mathrm{~m}$, both salinity and temperature reach local maxima, where the depth of the largest temperature anomaly is roughly lower than the depth of the largest salinity anomaly. While eddy-induced thermohaline anomalies in other regions are observed [58,59], the maximum depth at which these anomalies occur, while not the same, is limited to depths shallower than $400 \mathrm{~m}$.

\subsection{Abnormal Eddies}

To verify the accuracy of SLA data-detected eddies, SST data were used for a supplementary explanation. SST within 1.5 times the eddy radius was defined as the background SST field. In most previous studies, CEs (AEs) are often associated with cold (warm) nuclei. Therefore, CEs (AEs) are also called cold (warm) eddies. This result is usually obtained through comprehensive analysis, and it is assumed that these polarization types (CE or $\mathrm{AE}$ ) have similar characteristics. However, during the data processing phase, it was identified that there are unusual cases in which eddies detected in 
the same place and time were of opposing polarities. Such eddies are generally called 'abnormal eddies', which accounts for about $0.11 \%$ of the total number of eddies. As shown in Figure 16a, it can be observed that SST at the center of the CE is higher than at its boundary, while the opposite is true for the AE in Figure 16b; that is, CEs and AEs possess cold and warm cores, respectively. Sun et al. [48] found similar structures in the North Pacific and discovered that warm-cored CEs were mainly concentrated in the northwest and southeast Pacific, while cold-cored AEs were found primarily in the northeast Pacific Ocean. It is also observed that the number of abnormal eddies decreased year by year. Using the Euler eddy-counting method, a total of 335 of these abnormal eddies were detected in the BOB, of which 149 were AEs and 186 were CEs. In Figure 16c,d, it can be observed that both CEs and AEs are concentrated in the western BOB $\left(10-16^{\circ} \mathrm{N}, 80-85^{\circ} \mathrm{E}\right)$, and northeast of Sri Lanka $\left(9-10^{\circ} \mathrm{N}, 81-85^{\circ} \mathrm{E}\right)$, where there can be up to 30 eddies per $1^{\circ} \times 1^{\circ} \mathrm{bin}$. As compared with normal eddies, abnormal eddy lifecycles are longer, averaging about 5.6 weeks, and they have larger radii of about $124.29 \mathrm{~km}$. Moreover, approximately $51.9 \%$ of normal eddies morph into abnormal eddies during the maturation stage, and $30 \%$ in the dissipation stage. About $18 \%$ of eddies are converted into abnormal eddies collectively in the formation and maturation stages. These transformations occur mainly in January, March, July, and December. Abnormal eddies occur near the BOB retroreflection current where in winter, the southward flowing EICC meets the Northeast Monsoon Current and flows westward around Sri Lanka. In spring and summer, the current moves northward to become the western portion of anticyclonic circulation. The transformation of the EICC and multi-current region strongly corresponds with the distribution of abnormal eddies. Therefore, the formation of abnormal eddies may be related to the intrusion of equatorial and coastal Indian Ocean currents. To understand the specific mechanisms involved, further studies are required.
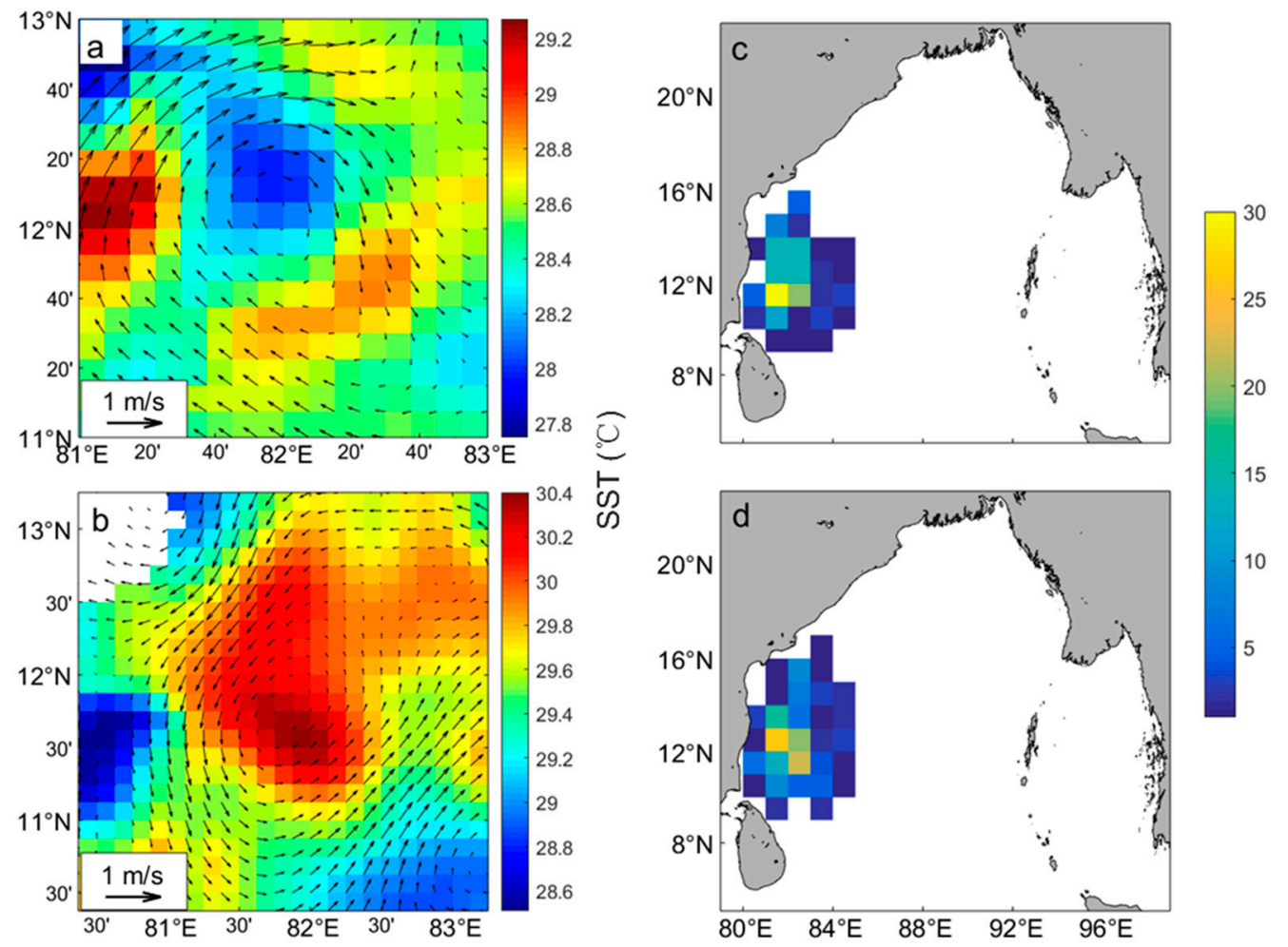

Figure 16. Abnormal eddy for AEs (a) and CEs (b) and spatial distribution (lifetime $\geq 4$ weeks) over $1^{\circ}$ $\times 1^{\circ}$ bins for AEs (c) and CEs (d), where the arrow indicates geostrophic velocity anomalies and the color indicates the temperature. 


\subsection{Effect of Eddy on Sea Surface Chlorophyll (Chl)}

The effects of mesoscale eddy on sea surface chlorophyll (Chl) in the BOB were studied based on SLA data and ocean color remote-sensing data. Eddies with lifespans exceeding four weeks were paired with Chl-a data on a time span ranging from 29 August 1997 to 31 December 2018. Over the 22-year period, background eddy Chl-a fields were matched to 875 CEs and 853 AEs. Based on the vigorous motion induced by mesoscale eddies, the surrounding seawater will be mixed, and its stratification affected. Upwelling induced by CEs transport bottom nutrients towards the surface, allowing for phytoplankton growth rates and Chl-a concentrations to increase (Figure 17a-f). By contrast, downwelling caused by AEs of what little surface nutrients may be available to the cold, dark ocean bottom stifles growth of the photosynthetic organisms (Figure 17g-1). To further study the changes in Chl-a distribution in CEs and AEs, Chl-a data ranging from the eddy's center to its boundary was defined as the inner-eddy Chl-a concentration, and everything outside this range, naturally, was the outer-eddy Chl-a concentration. Chl-a background fields with absolute values (inner-outer-eddy Chl-a concentrations) not less than $0.015 \mathrm{mg} / \mathrm{m}^{-3}$ were selected as the high (low) value area of the CE (AE) Chl concentration, accounting for $58 \%$ and $61 \%$ of the total numbers of eddies, respectively. That is, most CEs (AEs) caused Chl-a anomalies. As can be shown in each case, Chl-a takes on the general shape of the eddy, all of which are circular and are significantly different from surrounding waters. At the eddy center, $\mathrm{Chl}$-a concentrations are at their highest and gradually decrease with increasing distance from the center.

To study the differences in Chl-a concentrations between areas with and without eddies, both eddy polarities (hereinafter referred to as anomalous Chl eddies) underwent further quantitative analyses and the resulting Chl-a concentrations were averaged over the 22 years. Chl-a concentrations per unit area of positive and negative anomalous Chl eddy were measured at $0.2094 \pm 0.0733 \mathrm{mg} / \mathrm{m}^{3}$ and $0.1672 \pm 0.0462 \mathrm{mg} / \mathrm{m}^{3}$, respectively. In areas unaffected by Chl-a-containing eddies, Chl-a content was measured at $0.1884 \pm 0.0584 \mathrm{mg} / \mathrm{m}^{3}$, which accounted for approximately $89.97 \%$ of the value possessed by CEs in high Chl-a concentration values and $112.67 \%$ of AE values, and from this it was demonstrated that mesoscale eddies have an effect on Chl-a concentrations. Moreover, it was also observed that opposite patterns in Chl-a fields for CEs and AEs were observed. For CEs, Chl-a content was low, and for AEs, Chl-a was high. This may be related to other physical processes around a given eddy. Light availability is also a limiting factor in phytoplankton growth as if there is insufficient light for photosynthesis to occur, the concentration of Chl-a will be greatly reduced.

In order to more clearly show the changes of $\mathrm{Chl}$ inside and outside the eddy, the $\mathrm{Chl}$ a concentration observations were linearly interpolated onto a normalized grid of $+/-2.5 \mathrm{Ls}$, where Ls denoted the eddy radius, to fill in the missing data (Figure $17 \mathrm{a}, \mathrm{d}, \mathrm{g}, \mathrm{j}$ ), Then normalized, we converted the concentration of Chl-a centered on the eddy from a Cartesian to a polar coordinate system (Figure 17b,e,h,k). The change in Chl-a concentrations in the average unit area of different radial regions could then be estimated (Figure 17c,f,i,l). Figure 18a,b show the normalized Chl-a concentration in a mesoscale eddy as a function of different distances from the eddy center. While the overall trend of CEs and AEs is opposite, they both develop monotonously, and the maximum (minimum) values appear within two-times the eddy radius, and the normalized Chl-a concentration gradually decreases (increases) with increasing radial distance from the center. This remains true regardless of eddy polarity within a distance of 0.5 times the radius. However, the standard deviation is large at 0.015 . Beyond this range, the standard deviation drops to 0.0128 . Similarly, in Figure $17 \mathrm{c}, \mathrm{f}, \mathrm{i}, \mathrm{j}$, , it can be shown that within 0.5 times the eddy radius, $\mathrm{Chl}$-a concentrates reaches the local extreme value and gradually decreases as the distance from the center increases.

Here, changes in Chl-a concentration were assessed based on eddy evolution. Based on the Lagrangian eddy-counting method, the lifecycle of an eddy can be distributed proportionally from 0 to 1 . As previously identified, eddies can be divided into four stages: generation, intensification, maturation, and dissipation. To explore the changes in Chl-a concentration at the various stages, $\mathrm{Chl}-\mathrm{a}$ was also distributed proportionally from 0 to 1 . The difference in Chl-a concentration between 
inside and outside the eddy was now defined as the eddy anomaly. Figure 18c shows the number of eddies which exhibit Chl-a anomalies in the eddy's lifecycle. It can be seen that eddies with high (low) Chl-a concentrations often develop early in life and in later stages of life, eddies, based on polarity, exhibit different trends. For CEs, high Chl-a regions are produced in all other life stages except during the intensification period. For AEs, low Chl-a regions develop more frequently in the early and middle stages of maturity. There may be different mechanisms of Chl-a anomaly formation in eddy polarity. Previous studies have pointed out that anomalous Chl-a concentrations in the early stage of eddy formation may be related to eddy capture, while later periods may be related to eddy stirring the surrounding seawater and eddy-induced Ekman pumping [42]. Similarly, we normalized anomalous Chl-a concentrations in the different life stages to obtain the change of Chl-a throughout an eddy's lifecycle. Statistics indicated that the normalized Chl-a concentration during eddy formation and dissipation period was similar throughout the eddy lifecycle but changed sharply during the intensification and maturation periods. To further verify the anomalous Chl-a collective effect of eddies far exceeding other dynamic effects in the outside sea, anomalous Chl-a concentrations inside and outside the eddy were normalized. Figure 18e,f show changes of Chl-a concentration in the different life stages of CEs and AEs, respectively. Convex and concave shapes in $\mathrm{CE}$ and AE curves, respectively, are identified. There, for CE, there appear three peaks in anomalous Chl-a concentrations, corresponding to the early and late stages of intensification and the early stage of maturity. During the formation and dissipation stages, however, there is little difference in anomalous Chl-a concentrations, which instead showed a gradual regression to the initial state after drastic changes in eddy midlife. By contrast, CE anomalous Chl-a concentrations are slightly different. There are only two minimum values that gradually converge after reaching their maximum in the late intensification stage. Anomalous Chl-a concentrations during the formation and dissipation stages are very similar and soon return to their initial states. Comparing the changes in the anomalous Chl-a concentration in both eddy polarities, CEs mainly show active variability with abnormally high values, while AEs show steady and continuous development over long periods of time, with changes in late mature and mid-late intensification stages occurring very minutely. Comparing this with Figure 18c, the results are similar to the above findings. A high concentration of Chl-a in CEs develops more frequently in mature and intensification periods than in other stages of life. Low concentrations of Chl-a in AEs are mainly concentrated in the pre-mature stage. It is demonstrated that anomalous values in Chl-a surrounding the eddy are indeed caused by the eddy. Chl-a anomalies in the eddy formation and dissipation periods in Figure 18c may be related to other dynamic factors in the surrounding area, such as monsoons and SST. The specific mechanisms still require further study to be elucidated.

As shown in Figure 18d, changes in Chl-a at different eddy life stages are further quantified to obtain the change rate of Chl-a concentration per 1/10th of eddy life, where positive values indicate increases in Chl-a concentrations and negative values indicate decreases. Change rates are also different based on eddy polarity. CEs experience higher Chl-a change rates than AEs. For CEs, this value is estimated at an average of $0.0015 \mathrm{mg} / \mathrm{m}^{3} \mathrm{~d}$, reaching a maximum of $0.3379 \mathrm{mg} / \mathrm{m}^{3} \mathrm{~d}$. Chl-a growth rates are relatively high during eddy formation, accelerating further in the intensification period before decreasing slightly in the mature periods before experiencing greater reductions during eddy dissipation. It is worth noting that Chl-a concentrations at the halfway point of an eddy's life cycle show greater rates of decrease. In AEs, the rate of decrease in Chl-a concentration is similar most of the time at an average rate of $-0.00036 \mathrm{mg} / \mathrm{m}^{3} \mathrm{~d}$, but there is also a small period where Chl-a increases at a minute rate. Also different from CEs, AE Chl-a change rates are larger during eddy formation, late intensification, and mature periods. These values, however, are retarded from the onset of the mid-intensification to the dissipation periods. This then leads to anomalous Chl-a concentrations returning to its original state following an increase in growth rate. Comparing Figure 18e,f, we can see that the rate of change in Chl-a concentration is consistent with anomalous Chl-a in both eddy polarities. 

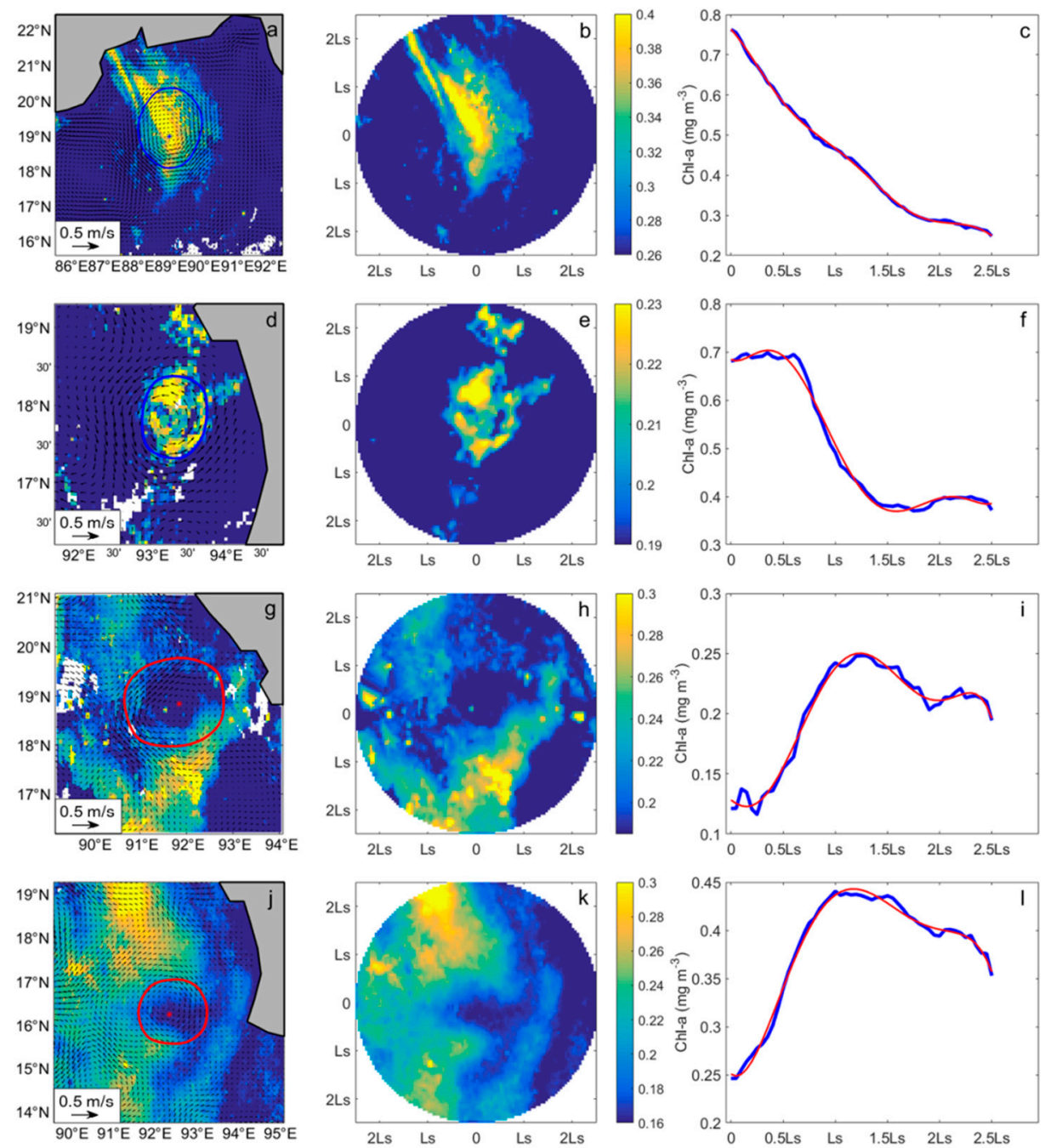

Figure 17. Schematic diagram of abnormal chlorophyll (Chl) eddies. $\mathrm{CE}$ is represented by (a-f), and AE is represented by $(\mathrm{g}-\mathbf{1})$. (a) A CE matched with $\mathrm{Chl}$ concentration data. Vectors represent geostrophic velocities. (b) Chlorophyll region is transformed into polar coordinates. (c) Distribution of the averaged chlorophyll as a function of the eddy radius. The peak of averaged $\mathrm{Chl}$ concentration locates around Ls, which denotes the eddy radius. Rho refers to the normalized distance from the eddy center related to Ls. Among them, blue is Chl data, and red is Fourier fitting curve. $(\mathbf{d}-\mathbf{f}),(\mathbf{g}-\mathbf{i}),(\mathbf{j}-\mathbf{l})$ have the same meaning as $(\mathbf{a}-\mathbf{c})$. 

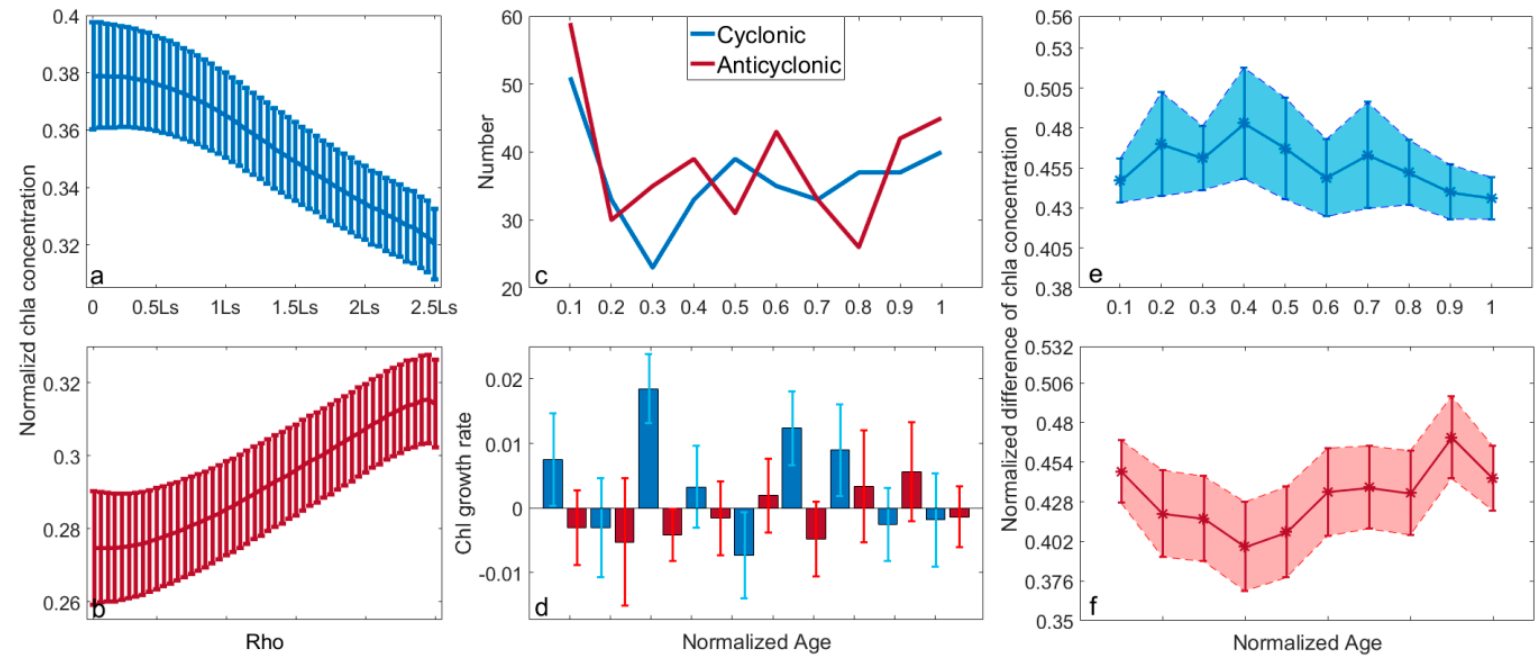

Figure 18. Averaged normalized $\mathrm{Chl}$ as a function of the eddy normalized radius for CEs (a) and AEs (b). (c) The number of vortices exhibiting high values of $\mathrm{Chl}$ in different eddy life stages. (d) Change rate of normalized Chl concentration in different life stages of eddy; changes in normalized Chl at different life stages for (e) CE and (f) AE. The error bar is defined as standard deviation.

\section{Discussion}

\subsection{The Mechanisms for Eddy Generation and Dissipation}

The mechanism of eddy generation and dissipation is diverse in different sea areas. Based on previous studies such as those conducted by Liu et al. [58] that found eddies in the north Pacific subtropical band are generated through baroclinic instability and wind stress, the Qin et al. [60] analysis which shows that CEs in the East China Sea are mainly affected by Kuroshio transport in addition to interference from the surrounding ocean and orographic wind blockage, and the discovery of Ji et al. [59] that eddies are generated near the Kuroshio Extension Region due to horizontal shear instability, it is apparent that for different regions, eddies are generated through a wide variety of mechanisms. For example, and relevant to the current subject, Chen et al. [21] suggest that for BOB eddies, baroclinic instability and the influence of wind stress are the principal mechanisms for eddy interannual variability. The formation of eddies in the Andaman Sea may also be related to the local topography. Chang et al. [25] in their analysis of the wind stress curl and eddy variability seasonality, find that wind stress curl is the primary driving force in mesoscale eddy production in the BOB. Westward-propagating Rossby waves as stimulated by Kelvin waves are also shown to have an impact on eddy formation. Figure 11 shows that eddies mostly generate in the Andaman Sea and the central part of the $\mathrm{BOB}$, and terminate in large numbers on the west coast of $\mathrm{BOB}$ and southwest of the Andaman Sea. Due to data limitations, this paper only analyzes the mechanisms of eddy formation and dissipation in the Andaman Sea.

In order to further analyze the causes of eddies generation and dissipation in the subregion, Figure 19 gives the seasonal changes in the formation, dissipation, and propagation of long-lived (lifecycles of no less than 10 weeks) eddies in the subregion. Similar to the entire study area, there are more eddies appearing in spring and winter, more AEs in winter than CEs, and the least number of eddies in the summer. What is different from the entire study area is that in the Andaman Sea, spring and winter trends are similar and autumn and summer trends are similar. Eddies dissipate least in the autumn. Moreover, eddy trajectories indicate that eddies are born mostly in the middle and south of the Andaman Sea $\left(9-13^{\circ} \mathrm{N}, 93-96^{\circ} \mathrm{E}\right)$, before spreading either west or southwest to the coast of the Andaman Islands and dying. CEs in the spring and autumn are mostly uniform in the meridional direction. In winter there are more AEs, with a mixed distribution of eddies in the central and western regions. A cluster of CEs dominates the southeast. Summer is unique: eddies of 
the same polarity cluster together. Furthermore, there are no detected eddies around the Andaman Islands, but there are some detected that flowed through gaps in between the islands. Topography in between the islands will strongly influence background oceanic fields as ocean currents flowing through the islands will cause the production of von Kármán eddies and wind stress curls will also play a role in eddy formation. Dong et al. [61] propose that due to the blocking effect of the island on the wind, positive wind stress curl may occur on the leeward side of the island. To demonstrate, Figure 20a-d give the multi-year average of the southwest and northeast monsoons' positive and negative wind stress curls. In Figure 20a,b, during both monsoons, wind blows through the Andaman Islands, leading to positive wind stress curls increasing at around $10^{\circ} \mathrm{N}$ to $2.05 \times 10^{-5}-4.22 \times 10^{-5}$. By contrast, when monsoon winds do not pass through the Andaman Islands, the wind stress curl is small and hovers at approximately $0.12 \times 10^{-5}-0.7 \times 10^{-5}$. The north-south distribution of the positive wind stress curl can be contrasted with east-west distributions of negative wind stress curls. In Figure 20c, it can be observed that summer winds blow through the islands and produce negative wind curls, reaching a minimum in the southeast area near land. In Figure 20d, winter winds produce a distribution of wind stress curls oriented with low values in the north, south, and east, with larger values in the western and central regions. Generally, positive wind stress curl in the Andaman Sea is more variable than negative wind stress curl, with significant variability exhibited in the summer and winter. When compared with Figure $19 \mathrm{~d}$,f, in areas where positive wind stress curl is greater during the summer and winter monsoons, more CEs are observed, thus lending credence to the idea that positive wind stress curl may be responsible for generating CEs in the area. While there is a certain correspondence between the negative wind stress curl and the generation of winter AEs, this is perhaps unrelated to the generation of summer AEs and thus may indicate that other factors may also contribute to eddy formation. With reference to Figures 4 and 11, it is seen that with the presence of a strong western boundary current, the distribution of eddy dissipation and EKE are correlated well with one another in the southern Andaman Sea. For example, Cheng et al. [22] show that eddy formation in the northwest Andaman Sea is related to coastal Kelvin waves. Here, from Figure 20e,f which depict a multi-year average of sea surface wind (monsoon) speed, we can see that summer winds are significantly more intense than winter winds, and so when summer winds attempt to blow through the Andaman Islands, they are instead effectively blocked by topography. Winter winds, by contrast, albeit weaker than summer winds, can blow through and may even experience accelerations on the magnitude of $0.4 \mathrm{~m} / \mathrm{s}$. Near land, winter and summer wind speeds in the north- and south-eastern seas present low values, while high speeds are observed in the central and southern Andaman Sea. With reference to Figure 2a,b, there are strong currents in the middle of the Andaman Sea, near the islands, and these are especially intense during the summer which corresponds to the geographical locations of more eddies previously observed in Figure 19d. This area is also characterized by strong winds and large EKE values and so it may be hypothesized that eddy generation in the eastern and north-eastern islands may be related to ocean circulation, wind, and topography. By contrast, referring to Figure 4a, high EKE values are apparent in the southern Andaman Sea and correlate well with both the strong oceanic current and wind fields. Therefore, eddy generation in the southwest may also be related to baroclinic pressure instability.

\subsection{Chl Rings}

In the statistical analysis of the influence of eddies on Chl-a, it is found that there are some structures different from the aforementioned abnormal $\mathrm{Chl}$ eddies. As suggested by $\mathrm{Xu}$ et al. [62], Chl-a ring structures are observed which account for only about $1.02 \%$ of the total number of detected eddies (Figure 21). Xu et al. [62] use geostrophic currents, Chl-a and SST data to study the influence mechanism of mesoscale eddies on Chl-a, creatively propose the structure of $\mathrm{Chl}$ rings in the ocean, and analyze various dynamic reasons for the formation of $\mathrm{Chl}$ rings caused by eddies. The structure of the Chl ring under the action of cyclones and anticyclones is similar, and they are all ring-shaped structures that extend outward from the center of the eddy, and are mostly formed in the intensification 
and mature stages of the eddy. Its average Chl concentration is the smallest at the center of the eddy, gradually increasing within a radius of 0.5 times its size, rapidly developing within a radius of $0.5-1.5$ times and reaching a local extremum, then gradually decreasing as the radius increases, this structure may related to local background field convection and wind stress.

Previous studies have shown that eddies affect $\mathrm{Chl}$ through a variety of mechanisms. For example, Kumar et al. [40] conclude that cyclones can inject nutrients into the ocean's nutrient-deficient waters during the southwest monsoon to increase ocean productivity. Chelton et al. [8] analyze the synergistic effect of sea surface height and Chl-a concentration, indicating that eddy rotation is the main mechanism that causes horizontal advection of Chl-a. Sabu et al. [63] study eddies and Chl-a in the northern part of the BOB. Results show that eddy-induced Ekman suction would cause Chl-a concentrations within the eddy to increase. Gonaduwage et al. [44] find that baroclinic instability is the main mechanism that causes eddy transport, and to some extent, local wind stress and forcing from the equator also contribute to the seasonal modulation of eddy heat transfer. Simultaneously, transport of nutrients from the seabed, submesoscale movements, and internal waves leading to isobaric lines, can all affect changes in Chl-a. As shown in Figure 18c, Chl-a anomalies already exist during the eddy formation period and subsequent studies have concluded that because CEs with high Chl-a concentrations and AEs with low Chl-a concentrations should form primarily during their intensification and maturation periods, there may be other factors outside the eddy which drive changes in Chl-a.
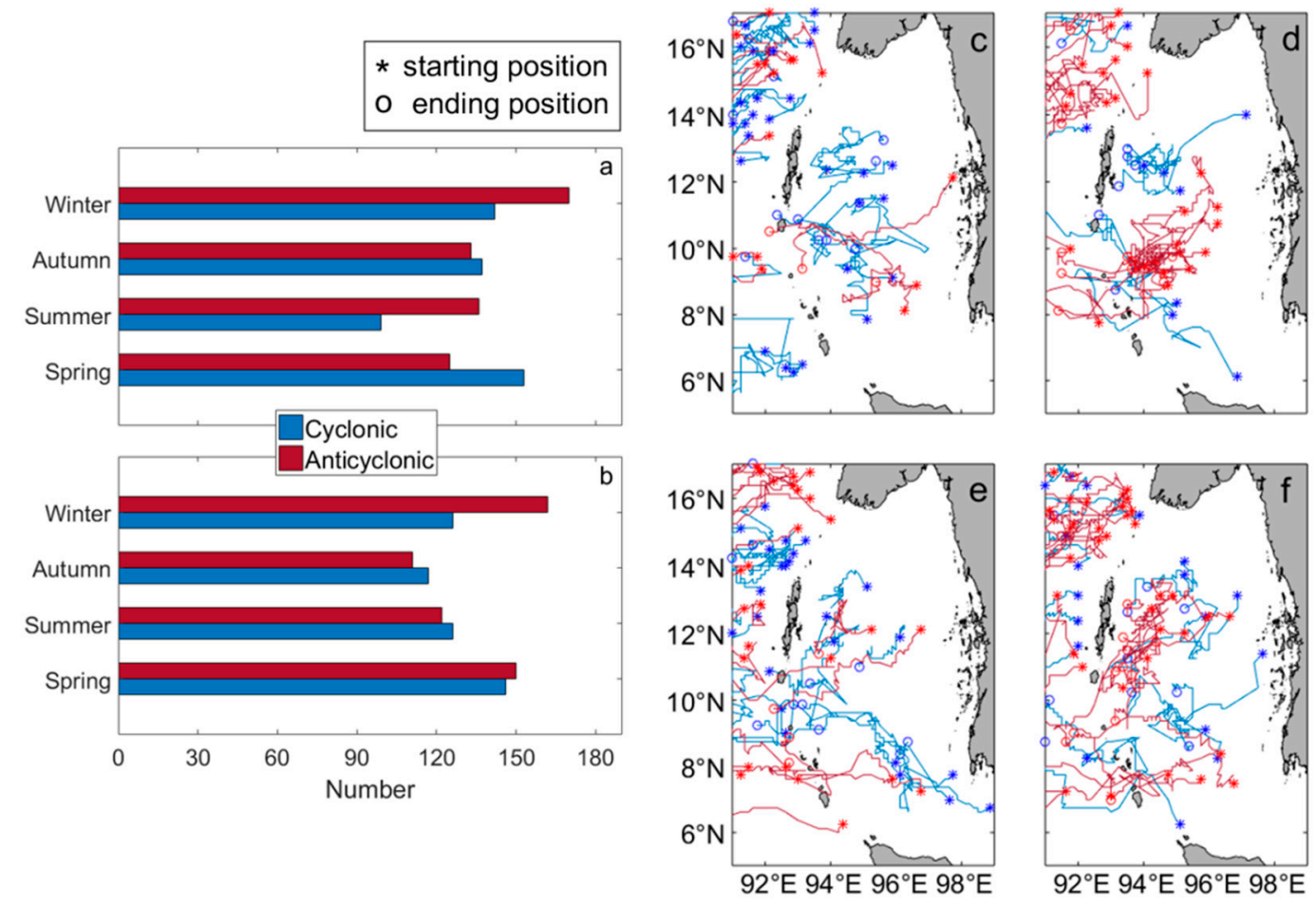

Figure 19. In the Andaman Sea, eddies with a life cycle of not less than 4 weeks produce (a) and die (b) seasonal changes, and the propagation map of eddies with a life cycle of not less than 10 weeks is (c) spring (d) summer (e) autumn (f) winter. 

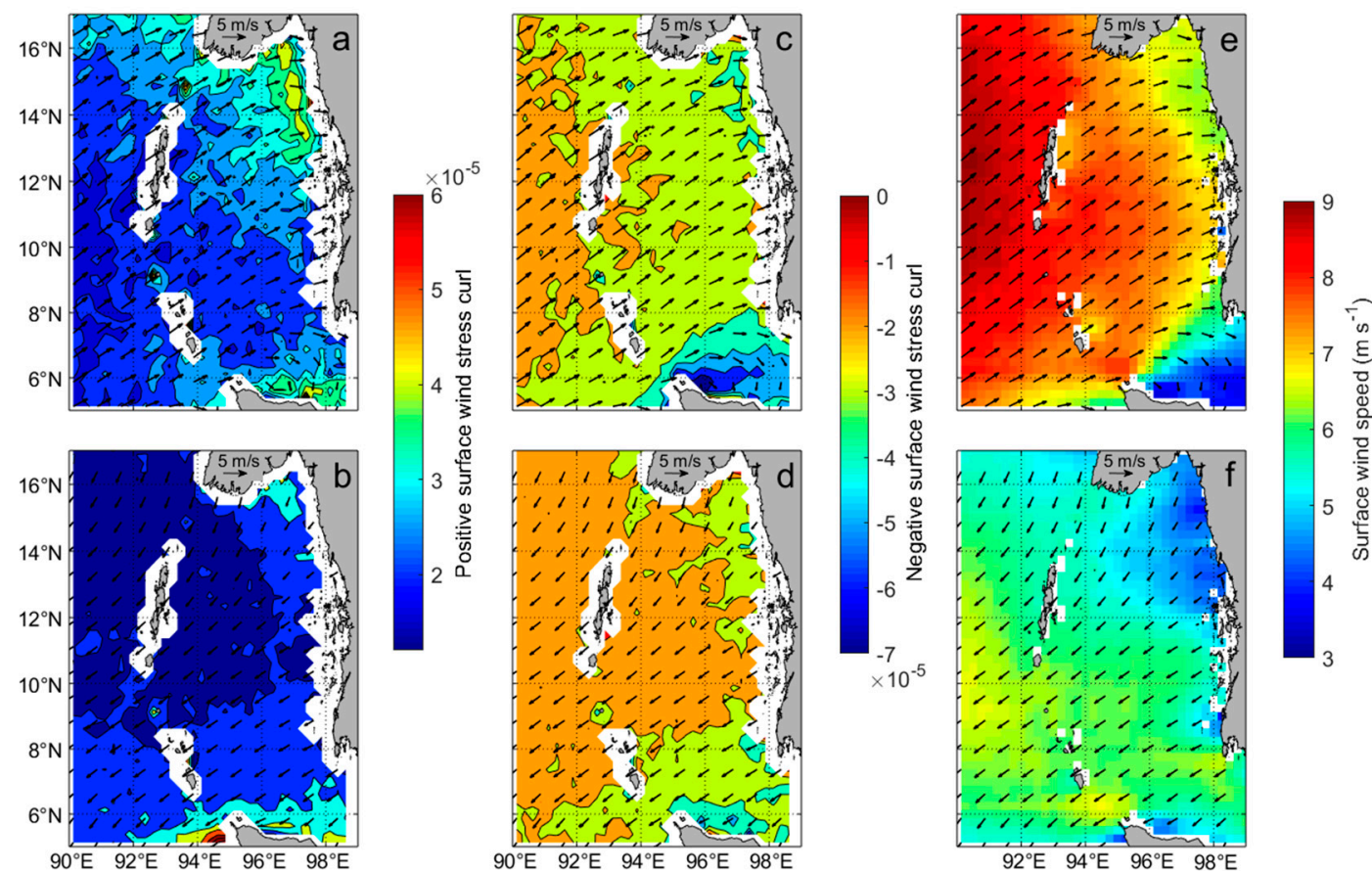

Figure 20. Multi-year mean positive wind stress curl in summer (a) and winter (b); multi-year mean negative wind stress curl in summer (c) and winter (d); multi-year average sea surface wind speed in summer (e) and winter (f). The vectors correspond to surface wind speed and direction. 

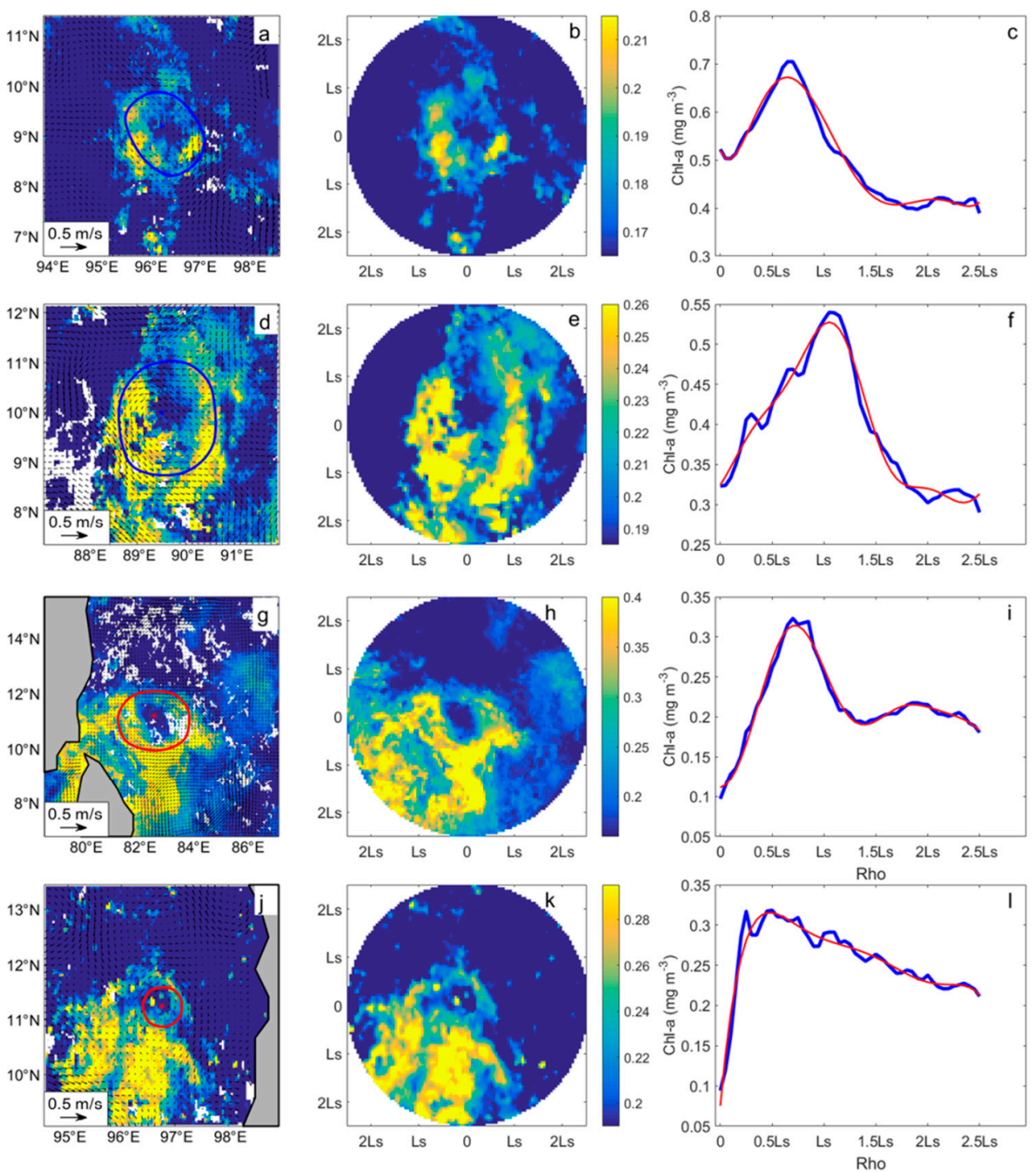

Figure 21. Schematic diagram of $\mathrm{Chl}$ rings. $\mathrm{CE}$ is represented by $(\mathbf{a}-\mathbf{f})$, and $\mathrm{AE}$ is represented by (g-1). (a) An CE matched with Chl concentration data. Vectors represent geostrophic velocities. (b) Chlorophyll region is transformed into polar coordinates. (c) Distribution of the averaged chlorophyll as a function of the eddy radius. The peak of averaged Chl concentration locates around Ls, which denotes the eddy radius. Rho refers to the normalized distance from the eddy center related to Ls. Among them, blue is Chl data, and red is Fourier fitting curve. $(\mathbf{d}-\mathbf{f}),(\mathbf{g}-\mathbf{i}),(\mathbf{j}-\mathbf{l})$ have the same meaning as $(\mathbf{a}-\mathbf{c})$.

\section{Conclusions}

In this paper, an array of datasets ranging from SLA, Argo T/S vertical profiles, Chl-a, SST and wind field data, in conjunction with a geometric feature-based automatic eddy detection algorithm, were used to study BOB eddies from 1993 to 2018, and the effects of their on Chl-a concentrations. Over the 26-year study period, Euler and Lagrangian methods of eddy-counting were employed to study the statistical properties of mesoscale eddies in the region. Basic characteristics such as eddy life cycle, radius, spatiotemporal changes, formation, and dissipation, as well as eddy parameters such as vorticity, strain rate and EKE were analyzed. The study showed that a total of 2358 eddies with lifespans greater than or equal to four weeks were detected in the BOB, of which 1237 were CEs and 1121 were AEs. Spatially, eddies mostly inhabited the western and central BOB, Andaman Sea, and the island of Sri Lanka, and were mostly spread out in the southwest direction. Temporally, there was no 
obvious interannual variation of eddies over the 26-year study period and so, the years with either large or small numbers of eddies may be linked with the ENSO and La Niña phenomena. However, on a seasonal scale, most eddies were formed in the spring, followed by autumn and winter, with the least appearing in the summer. Other studies conducted by Vinayachandran et al. [64] and Schaott and Mccreary [65] suggest that EICC variability caused by monsoon activity and intrusion of the southwest monsoon current from the Indian Ocean is the primary reason for the appearance of more eddies in the spring. Through a comparative analysis, it is suggested that the four parameters of eddy radii, vorticity, strain rate and EKE, all possess similar trends in that they experience their greatest levels of change in the eddy formation and dissipation stages, and develop more gradually in their midlives. Moreover, CEs are found to be generated more frequently in the spring and summer, while AEs are generated principally in the summer. Research also indicates that regardless of eddy polarity, all eddies roughly dissipate in the Andaman Sea and the central BOB, disappearing almost completely in the western BOB. Previous studies have suggested that global western boundary currents are eddy graveyards [66], and this notion is well supported in the present investigation. Combined with the wind field data, it is found that the eddy generation in the east and northeast of the Andaman Islands may be related to the interaction of circulation, wind and topography, and southwest may also be related to baroclinic pressure instability. In addition, Argo T/S profiles suggest that eddies can cause the appearance of $T / S$ anomalies in the upper ocean to maximum depths of 150-200 m.

Then, we used SST data to detect abnormal eddies, which accounted for about $0.11 \%$ of the total eddies, and the number of $\mathrm{CE}$ warm eddies and $\mathrm{AE}$ cold eddies were equal. Most of them gathered from Sri Lanka to the northeast, near the retroreflection of the BOB. The formation may be related to the equatorial Indian Ocean runoff intrusion and the coastal currents of the Indian Ocean.

Finally, sea surface Chl-a data were used to explore the effect of eddies on its distribution. Based on the analysis, CEs can increase the concentration of $\mathrm{Chl}$ in surrounding waters, while AEs are opposite. It is determined that $\mathrm{CEs}$ with high $\mathrm{Chl}$-a concentrations are mostly distributed throughout the central and eastern portions of the BOB, while AEs with low Chl-a concentrations are distributed in the south and west BOB. Chl-a concentrations within eddies are defined as anomalous Chl-a eddies. It was found that with increasing radial distance from an eddy's center, a monotonous trend was observed for Chl-a concentrations in that dramatic changes in concentrations occurred within 0.5-1 times the eddy radius. Changes in concentrations were also different throughout an eddy's lifecycle. During eddy formation, Chl-a concentrations are minute and stable, before being rapidly altered during the intensification stage, reaching its maximum. During the early and late eddy maturation stages, Chl-a concentrations would begin to return close to its initial eddy formation state. During the eddy's midlife, a local extremum is achieved during the mid and late intensification and mature periods. Furthermore, in the statistical analysis of the effects of eddies on $\mathrm{Chl}-\mathrm{a}$, it was found that there were still a few $\mathrm{Chl}$ ring structures in the studied sea area, the number of which accounted for about $1.02 \%$ of the total number of matched eddies. This structure was mostly formed in the intensification and mature periods of an eddy, which may be related to the effect of local background field convection and wind stress. Since this study was mainly based on a statistical analysis, the study was limited in that a quantitative analysis of dynamical processes and subsurface Chl-a distributions could not be performed. Consequently, future research could be geared towards understanding dynamical processes and subsurface Chl-a distributions.

Author Contributions: Conceptualization, X.Y. and C.D.; methodology, X.Y., G.X. and C.D.; validation, X.Y. and C.D.; formal analysis, X.Y.; investigation, X.Y.; resources, C.D.; data curation, X.Y.; writing-original draft preparation, X.Y. and C.D.; writing-review and editing, X.Y., C.D., W.S., Y.L. and C.X. All authors have read and agreed to the published version of the manuscript.

Funding: This study is financially supported by The National Key Research and Development Program of China under contract No.2017YFA0604100, 2016YFA0601803, and 2016YFC1401407; the National Natural Science Foundation of China under contract No.41906008,41476022, 41490643, and 41706008; the Startup Foundation for Introducing Talent of Nanjing University of Information Science and Technology under contract No.2019r049, 2014r072; the Program for Innovation Research and Entrepreneurship team in Jiangsu Province under contract No.2191061503801; the Guangdong Basic and Applied Basic Research Foundation contract 2019A1515110840, 
and Research Startup Foundation of Guangdong Ocean University (R20009), the State Key Laboratory of Tropical Oceanography, South China Sea Institute of Oceanology, Chinese Academy of Sciences (No. LTO1902).

Acknowledgments: The altimeter products were produced by Ssalto/Duacs and distributed by Aviso, with support from Cnes (https://cds.climate.copernicus.eu/). The ocean color data were obtained from the Globcolour database provided by http://hermes.acri.fr. The AVHRR SST product data were obtained from the NASA JPL Web site. The Wind field data is acquired from the ASCAT version 2.1 dataset. Argo float data used here were collected and made freely available by Argo (http://www.argo.net/), and its contributing national programs. The authors are thankful to Brandon J Bethel for proofreading and providing constructive comments, which improved the overall English level of the paper. We thank the editor and two anonymous reviewers for their constructive comments and helpful suggestions on an earlier version of the manuscript.

Conflicts of Interest: The authors declare no conflict of interest.

\section{References}

1. Wang, H.; Liu, D.; Zhang, W.; Li, J.; Wang, B. Characterizing the Capability of Mesoscale Eddies to Carry Drifters in the Northwest Pacific. J. Oceanol. Limnol. 2020, 1-18. [CrossRef]

2. Stammer, D. On Eddy Characteristics, Eddy Transports, and Mean Flow Properties. J. Phys. Oceanogr. 1998, 28, 727-739. [CrossRef]

3. Qiu, B.; Chen, S. Eddy-Induced Heat Transport in the Subtropical North Pacific from Argo, TMI, and Altimetry Measurements. J. Phys. Oceanogr. 2005, 35, 458-473. [CrossRef]

4. Gaube, P.; Mcgillicuddy, D.J.; Chelton, D.B.; Behrenfeld, M.J.; Strutton, P.G. Regional Variations in the Influence of Mesoscale Eddies on Near-surface Chlorophyll. J. Geophys. Res. 2014, 119, 8195-8220. [CrossRef]

5. Holland, W.R.; William, R. The Role of Mesoscale Eddies in the General Circulation of the Oceannumerical Experiments using a Wind-driven Quasi-geostrophic Model. J. Phys. Oceanogr. 1978, 8, 363-392. [CrossRef]

6. McWilliams, J.C.; Flierl, G.R. On the Evolution of Isolated Non-linear Vortices. J. Phys. Oceanogr. 1979, 9, 1155-1182. [CrossRef]

7. Chelton, D.B.; Schlax, M.C.; Samelson, R.M.; Szoeke, R.A.D. Global Observations of Large Oceanic Eddies. Geophys. Res. Lett. 2007, 34, L15606. [CrossRef]

8. Chelton, D.B.; Schlax, M.G.; Samelson, R.M. Global Observations of Nonlinear Mesoscale Eddies. Progr. Oceanogr. 2011, 91, 167-216. [CrossRef]

9. Gruber, N.; Lachkar, Z.; Frenzel, H.; Marchesiello, P.; Plattner, G.K. Eddy-induced Reduction of Biological Production in Eastern Boundary Upwelling Systems. Nat. Geosci. 2011, 4, 787-792. [CrossRef]

10. Dong, C.; Mcwilliams, J.C.; Liu, Y.; Chen, D. Global Heat and Salt Transports by Eddy Movement. Nat. Commun. 2014, 5, 3294. [CrossRef]

11. Petersen, M.R.; Williams, S.J.; Maltrud, M.E.; Hecht, M.W.; Hamann, B. A Three-dimensional Eddy Census of a High-resolution Global Ocean Simulation. J. Geophys. Res. 2013, 118, 1759-1774. [CrossRef]

12. Sun, W.; Dong, C.; Wang, R.; Liu, Y.; Yu, K. Vertical Structure Anomalies of Oceanic Eddies in the Kuroshio Extension region. J. Geophys. Res. 2017, 122, 1476-1496. [CrossRef]

13. Yoshida, K. A Theory of the Cromwell Current (the equatorial undercurrent) and of the Equatorial upwelling-An Interpretation in a Similarity to a Coastal Circulation. J. Oceanogr. Soc. Jpn. 1959, 15, 159-170. [CrossRef]

14. Wyrtki, K. An Equatorial Jet in the Indian Ocean. Science 1973, 181, 262-264. [CrossRef]

15. Iskandar, I.; Michael, J.M. Dynamics of Wind-forced Intraseasonal Zonal Current Variations in the Equatorial Indian Ocean. J. Geophys. Res. 2011, 116, C06019. [CrossRef]

16. Goswami, B.N.; Rao, S.A.; Sengupta, D.; Chakravorty, S. Monsoons to Mixing in the Bay of Bengal: Multiscale Air-sea Interactions and Monsoon Predictability. Oceanography 2016, 29, 18-27. [CrossRef]

17. Babu, M.T.; Kumar, P.S.; Rao, D.P. A Subsurface Cyclonic Eddy in the Bay of Bengal. J. Mar. Res. 1991, 49, 403-410. [CrossRef]

18. Sanilkumar, K.V.; Kuruvilla, T.V.; Jogendranath, D.; Rao, R.R. Observations of the Western Boundary Current of the Bay of Bengal from a Hydrographic Survey During March 1993. Deep Sea Res. 1997, 44, 1-145. [CrossRef]

19. Sarma, Y.V.B.; Rao, E.P.R.; Saji, P.K.; Sarma, V.V.S.S. Hydrography and Circulation of the Bay of Bengal during withdrawal Phase of the Southwest Monsoon. Oceanologica Acta. 1999, 22, 453-471. [CrossRef] 
20. Eigenheer, A.; Quadfasel, D. Seasonal Variability of the Bay of Bengal Circulation from TOPEX/Poseiden Altimetry. J. Geophys. Res. 2000, 105, 3243-3252. [CrossRef]

21. Chen, G.; Wang, D.; Hou, Y. The Features and Interannual Variability Mechanism of Mesoscale Eddies in the Bay of Bengal. Cont. Shelf Res. 2012, 47, 178-185. [CrossRef]

22. Cheng, X.; Xie, S.P.; Mccreary, J.P.; Qi, Y.; Du, Y. Intraseasonal Variability of Sea Surface Height in the Bay of Bengal. J. Geophys. Res. 2013, 118, 816-830. [CrossRef]

23. Cui, W.; Yang, J.; Ma, Y. A Statistical Analysis of Mesoscale Eddies in the Bay of Bengal from 22-year Altimetry Data. Acta Oceanol. Sin. 2016, 35, 16-27. [CrossRef]

24. Dandpat, S.; Chakraborty, A. Mesoscale Eddies in the Western Bay of Bengal as Observed from Satellite Altimetry in 1993-2014: Statistical Characteristics, Variability and Three-dimensional Properties. IEEE J-STARS 2017, 9, 5044-5054. [CrossRef]

25. Chang, J.; Qiu, Y.; Lin, X.; Jing, C. General Features and Seasonal Variation of Mesoscale Eddies in the Bay of Bengal. J. Appl. Oceanogr. 2019, 38, 150-158. (In Chinese) [CrossRef]

26. Babin, S.M.; Carton, J.; Wiggert, J.D. Satellite Evidence of Hurricane-induced Phytoplankton Blooms in an Oceanic Desert. J Geophys. Res. 2004, 109, 325-347. [CrossRef]

27. Longhurst, A.; Sathyendranath, S.; Platt, T.; Caverhill, C. An Estimate of Global Primary Production in the Ocean from Satellite Radiometer Data. J. Plankton Res. 1995, 17, 1245-1271. [CrossRef]

28. Antoine, D.; Andre, J.M.; Morel, A. Oceanic Primary Production: 2. Estimation at Global Scale from Satellite (coastal zone color scanner) Chlorophyll. Global Biogeochem. Cycles 1996, 10, 57-69. [CrossRef]

29. Field, C.B.; Behrenfeld, M.J.; Randerson, J.T.; Falkowski, P. Primary Production of the Biosphere: Integrating Terrestrial and Oceanic Components. Science 1998, 281, 237-240. [CrossRef]

30. McGillicuddy, D.J.; Robinson, A.R.; McCarthy, J.J. Coupled Physical and Biological Modelling of the Spring Bloom in the North Atlantic (II): Three dimensional Bloom and Post-bloom Processes. Deep Sea Res. 1995, 42, 1359-1398. [CrossRef]

31. Martin, A.P.; Richards, K.J. Mechanisms for Vertical Nutrient Transport within a North Atlantic Mesoscale Eddy. Deep Sea Res. 2001, 757-773. [CrossRef]

32. Rafael, G.Q.; Pascual, A.; Damiá, G.; Ricardo, A. Influence of Mesoscale Physical Forcing on Trophic Pathways and Fish Larvae Retention in the Central Cantabrian Sea. Fish. Oceanogr. 2004, 13, 351-364. [CrossRef]

33. Falkowski, P.G.; Ziemann, D.; Kolber, Z.; Bienfang, P.K. Role of Eddy Pumping in Enhancing Primary Production in the Ocean. Nature 1991, 352, 55-58. [CrossRef]

34. Oschlies, A.; Garcon, V. Eddy-induced Enhancement of Primary Production in a Model of the North Atlantic Ocean. Nature 1998, 394, 266-269. [CrossRef]

35. Letelier, R.M.; Karl, D.M.; Abbott, M.R.; Flament, P.; Freilich, M.; Lukas, R. Role of Late Winter Mesoscale Events in the Biogeochemical Variability of the Upper Water Column of the North Pacific Subtropical Gyre. J. Geophys. Res. 2000, 105, 28723-28739. [CrossRef]

36. Oschlies, A. Nutrient Supply to the Surface Waters of the North Atlantic: A Model Study. J. Geophys. Res. 2002, 107, 1-13. [CrossRef]

37. Mcgillicuddy, D.J.; Anderson, L.A.; Doney, S.C.; Maltrud, M.E. Eddy-driven Sources and Sinks of Nutrients in the Upper Ocean: Results from a $0.1^{\circ}$ Resolution Model of the Noth Atlantic. Glob. Biogeochem. Cycles 2003, 17, 1035. [CrossRef]

38. Murtugudde, R.G.; McCreary, J.P.; Busalacchi, A.J. Oceanic Processes Associated with Anomalous Events in the Indian Ocean with Relevance to 1997-1998. J. Geophys. Res. 2000, 105, 3295-3306. [CrossRef]

39. Vinayachandran, P.N. Observations of Barrier Layer Formation in the Bay of Bengal during Summer Monsoon. J. Geophys. Res. 2002, 107, 8018. [CrossRef]

40. Kumar, P.S.; Nuncio, M.; Narvekar, J.; Kumar, A.; Sardesai, S.; De Souza, S.N.; Mangesh, G.; Ramaiah, N.; Madhupratap, M. Are Eddies Nature's Trigger to Enhance Biological Productivity in the Bay of Bengal? Geophys. Res. Lett. 2004, 31. [CrossRef]

41. Kumar, P.S.; Nuncio, M.; Ramaiah, N.; Sardesai, S.; Narvekar, J.; Fernandes, V.; Paul, J. Eddy-mediated Biological Productivity in the Bay of Bengal during Fall and Spring Intermonsoons. Deep Sea Res. 2007, 54, 1619-1640. [CrossRef]

42. Chelton, D.B.; Gaube, P.; Schlax, M.G.; Early, J.J.; Samelson, R.M. The Influence of Nonlinear Mesoscale Eddies on Near-surface Oceanic Chlorophyll. Science 2011, 334, 328-332. [CrossRef] [PubMed] 
43. Singh, A.; Gandhi, N.; Ramesh, R.; Prakash, S. Role of Cyclonic Eddy in Enhancing Primary and New Production in the Bay of Bengal. J. Sea. Res. 2015, 97, 5-13. [CrossRef]

44. Gonaduwage, L.P.; Chen, G.; Michael, J.; Priyadarshana, T.; Huang, K.; Wang, D. Meridional and Zonal Eddy-induced Heat and Salt Transport in the Bay of Bengal and their Seasonal Modulation. J. Geophys. Res. 2019, 124, 8079-8101. [CrossRef]

45. Kumar, P.S.; Muraleedharan, P.M.; Prasad, T.G.; Gauns, M.; Ramaiah, N.; de Souza, S.N.; Sardesai, S.; Madhupratap, M. Why is the Bay of Bengal Less Productive during Summer Monsoon Compared to the Arabian Sea? Geophys. Res. Lett. 2002, 29, 1-4. [CrossRef]

46. Nencioli, F.; Dong, C.; Dickey, T.; Washburn, L.; Mcwilliams, J.C. A Vector Geometry Based Eddy Detection Algorithm and its Application to High-resolution Numerical Model Products and High-frequency Radar Surface Velocities in the Southern California Bight. J. Atmos. Ocean. Technol. 2010, 27, 564-579. [CrossRef]

47. Sun, W.; Dong, C.; Tan, W.; Liu, Y.; He, Y.; Wang, J. Vertical Structure Anomalies of Oceanic Eddies and Eddy-induced Transports in the South China Sea. Remote Sens. 2018, 10, 795. [CrossRef]

48. Sun, W.; Dong, C.; Tan, W.; He, Y. Statistical Characteristics of Cyclonic Warm-Core Eddies and Anticyclonic Cold-core Eddies in the North Pacific Based on Remote Sensing Data. Remote Sens. 2019, 11, 208. [CrossRef]

49. Liu, Y.; Dong, C.; Liu, X.; Dong, J. Antisymmetry of Oceanic Eddies across the Kuroshio over a Shelfbreak. Sci. Rep. 2017, 7, 6761. [CrossRef]

50. Lin, X.; Dong, C.; Chen, D.; Liu, Y.; Yang, J.; Zou, B. Three-dimensional Properties of Mesoscale Eddies in the South China Sea Based on Eddy-resolving Model Output. Deep Sea Res. 2015, 99, 46-64. [CrossRef]

51. Amores, A.; Monserrat, S.; Marcos, M. Vertical Structure and Temporal Evolution of an Anticyclonic Eddy in the Balearic Sea (western Mediterranean). J. Geophys. Res. 2013, 118, 2097-2106. [CrossRef]

52. Dong, C.; Mavor, T.; Nencioli, F.; Jiang, S.; Uchiyama, Y.; Mcwilliams, J.C.; Dickey, T.; Ondrusek, M.; Zhang, H.; Clark, D.K. An Oceanic Cyclonic Eddy on the Lee Side of Lanai Island, Hawai'i. J. Geophys. Res. 2009, 114, C10008. [CrossRef]

53. Wen, Z.; Hu, H.; Zhang, N.; Lei, L.; Bai, H. Different Influences of Mesoscale Oceanic Eddies on the North Pacific Subsurface Low Potential Vorticity Water Mass between Winter and Summer. J. Geophys. Res. 2020, 125. [CrossRef]

54. Jiménez-Muñoz, J.C.; Mattar, C.; Barichivich, J.; Santamaría-Artigas, A.; Takahashi, K.; Malhi, Y.; Sobrino, J.A.; Van Der Schrier, G. Record-breaking Warming and Extreme Drought in the Amazon Rainforest during the Course of El Niño 2015-2016. Sci. Rep. 2016, 6, 33130. [CrossRef]

55. Qiu, Y.; Li, L.; Zhou, X. Sir Lanka Code Eddy and its Generation Mechanism Analysis. J. Top. Ocean Graphy 2008, 27, 45-51. (In Chinese) [CrossRef]

56. Roman-Stork, H.L.; Subrahmanyam, B.; Trott, C.B. Mesoscale Eddy Variability and its Linkage to Deep Convection over the Bay of Bengal using Satellite Altimetric Observations. Adv. Space Res. 2019. [CrossRef]

57. Sang, P.; Pascual, A.; Rodriguez-Santana, A.; Machin, F.; Mason, E.; McWilliams, J.; Pelegri, J.; Dong, C.; Rubio, A.; Aristegui, J.; et al. Canary Eddy Corridor: A Majorpathway for Long-lived Eddies in the Subtropic North Atlantic Ocean. Deep Sea Res. 2009, 8, 2100-2114. [CrossRef]

58. Liu, Y.; Dong, C.; Guan, Y.; Chen, D.; McWilliams, J.C.; Nencioli, F. Eddy Analysis in the Subtropical Zonal Band of the North Pacific Ocean. Deep Sea Res. 2012, 68, 54-67. [CrossRef]

59. Ji, J.; Dong, C.; Zhang, B.; Liu, Y. An Oceanic eddy Statistical Comparison using Multiple Observational Data in the Kuroshio Extension Region. Acta Oceanol. Sin. 2017, 36, 1-7. [CrossRef]

60. Qin, D.; Wang, J.; Liu, Y.; Dong, C. Eddy Analysis in the Eastern China Sea using Altimetry Data Frontiers of Earth Science. Front. Earth Sci. 2015, 9, 709-721. [CrossRef]

61. Dong, C.; McWilliams, J.C. A Numerical Study of Island Wakes in the Southern California Bight. Cont. Shelf Res. 2007, 27, 1233-1248. [CrossRef]

62. Xu, G.; Dong, C.; Liu, Y.; Gaube, P.; Yang, J. Chlorophyll Rings around Ocean Eddies in the North Pacific. Sci. Rep. 2019, 9, 9. [CrossRef] [PubMed]

63. Sabu, P.; Devi, C.R.A.; Lathika, C.T.; Sanjeevan, V.N.; Gupta, G.V.M. Characteristics of a Cyclonic Eddy and its Influence on Mesozooplankton Community in the Northern Bay of Bengal during Early Winter Monsoon. Environ. Monit. Assess. 2015, 187, 1-19. [CrossRef] [PubMed]

64. Vinayachandran, P.N.; Masumoto, Y.; Mikawa, T.; Yamagata, T. Intrusion of the Southwest Monsoon Current into the Bay of Bengal. J. Geophys. Res. 1999, 104, 11077-11085. [CrossRef] 
65. Schott, F.A.; Mccreary, J.P. The Monsoon Circulation of the Indian Ocean. Prog. Oceanogr. 2001, 51, 1-123. [CrossRef]

66. Zhai, X.; Johnson, H.L.; Marshall, D.P. Significant Sink of Ocean-eddy Energy near Western Boundaries. Nat. Geosci. 2010, 608-612. [CrossRef]

Publisher's Note: MDPI stays neutral with regard to jurisdictional claims in published maps and institutional affiliations.

(C) 2020 by the authors. Licensee MDPI, Basel, Switzerland. This article is an open access article distributed under the terms and conditions of the Creative Commons Attribution (CC BY) license (http://creativecommons.org/licenses/by/4.0/). 